\title{
Regional Fertility Transition in India: An Analysis Using Synthetic Parity Progression Ratios
}

\author{
Thomas Spoorenberg ${ }^{1}$ and Premchand Dommaraju ${ }^{2}$ \\ ${ }^{1}$ United Nations Population Division, Department of Economic and Social Affairs, 2 United Nations Plaza, Room DC2-1908, \\ New York, NY 10017, USA \\ ${ }^{2}$ Division of Sociology, School of Humanities and Social Sciences, Nanyang Technological University, Singapore 637332
}

Correspondence should be addressed to Thomas Spoorenberg, thomas.spoorenberg@gmail.com

Received 23 November 2011; Accepted 30 January 2012

Academic Editor: David R. Phillips

Copyright (C) 2012 T. Spoorenberg and P. Dommaraju. This is an open access article distributed under the Creative Commons Attribution License, which permits unrestricted use, distribution, and reproduction in any medium, provided the original work is properly cited.

This paper examines various aspects of regional fertility transition in India. Using nationally representative data from three rounds of National Family Health Surveys (NFHSs) conducted in India, we compare and contrast fertility patterns in six regions of India for the period between 1977 and 2004. To study the fertility patterns, we use synthetic parity progression ratios which, besides providing estimates for average lifetime parity, also allow for decomposition of lifetime parity by birth order. The paper also examines changes in birth intervals over time and across the six regions. The results confirm the persistence of regional differences in fertility. However, in all regions fertility is declining and it is possible that fertility rates will converge in the near future. The main reason for fertility decline in all regions is the reduction in third- and higher-order births. There has not been any significant decline in first and second births, even in regions with low fertility. In addition to the discussion of the substantive results, the paper also comments on the quality of NFHS data.

The views expressed in this paper are those of the author and do not necessarily reflect the views of the United Nations. Its contents have not been formally edited and cleared by the United Nations

\section{Introduction}

The broad spatial contours of Indian fertility patterns are well known, but the specifics about the spatial heterogeneity in fertility decline remain unclear. Often, the near or below replacement fertility in much of south India is contrasted with high fertility in parts of north India. However, fertility heterogeneity is not restricted to the north-south dichotomy alone. There are differences within and between other regions in India, though they are not as pronounced as the north-south divide. Despite the differences in the current level, fertility has been declining at a varying pace in almost all parts of the country. In this descriptive paper, we examine in detail the characteristics of the fertility decline in various regions of the country by examining parity progression ratios and mean birth intervals for a 25-year period between 1977 and 2004.
Parity progression ratios (PPRs) are important tools in understanding fertility transitions for several reasons. First, they capture the contingent nature of fertility behavior: the decision to have a child is often shaped by the number of previous births a woman has had. Second, they can be used to gauge whether certain family sizes, in terms of number of children, are becoming common. Third, the decomposition of the PPRs can be used to estimate the relative contribution of reduction of births at different orders to overall fertility decline. Finally, calculating PPRs using three rounds of survey data allows comparison of the estimate from the various rounds and to assess the data quality. Spoorenberg's [1] study of fertility change in India (at the national level) using PPRs demonstrates these benefits. This paper extends the analysis by looking at regional patterns of PPRs and examines PPRs for six regions in India. 


\section{Indian Context}

Population stabilization through fertility reduction has been a key policy objective since the 1950s. The most recent articulation of this objective can be found in the National Population Policy, 2000, which states its medium-term goal as reducing Total Fertility Rate (TFR) to replacement level by 2010 and to achieve a stable population by 2045. As with ambitious objectives of the past population policies, the goal of replacement fertility has not been achieved (TFR was 2.85 in 2005-2006; [2]). The formulation of optimistic and ambitious demographic goals has a long history-for instance, the population policy in the early 1960s called for achieving a CBR of 25 by 1972, a goal achieved only in 2002 [3].

The optimistic tone of the national policies might not have changed over the years, but the various policies formulated to achieve these goals have changed with time. Earlier policies took a programmatic approach by setting contraceptive and sterilization targets. This approach had its heyday during the "Emergency Period" in the mid-1970s when targets were vigorously and, in some areas, forcefully implemented. After the aggressive measures of this period the emphasis of the population policy shifted to "Family Welfare" that emphasized child and maternal health. The Cairo population conference of 1994 brought two significant changes to population policies in the late 1990s: targets were abolished and planning and implementation were decentralized. Under the current policy, state governments are free to implement their own programs consistent with the framework set out in the National Population Policy, with bulk of the funding for the programs provided by the central (union) government [4]. The devolution of policy making to the states has resulted in diverse policies, some of which have punitive measures. States in the south that have achieved substantial fertility reduction have continued with nonrestrictive measures whereas states in the north with high fertility have introduced restrictive measures such as barring those "with children beyond a specified number from holding or seeking political office at the local level," amongst other measures [5].

Even during the time when population policies were implemented by the central government, the implementation and enforcement of the various policies was not uniform across the states. Different states had different demographic and socioeconomic and political realities that could not be easily erased. The formulation of a single National Population Policy with a single national goal ignores this social and demographic diversity. Regardless of the intent, the effectiveness of the population policies has been limited to areas that have witnessed social, political, and economic changes. As Guilmoto [6] has pointed out "the much publicized government intervention in family planning had a favorable impact only in areas where social change-fueled by urbanization and off-farm employment, the rising returns on educational investments in children, and a more open political space- - had already reshaped gender arrangements."

Progressive gender arrangements in the south that grant women greater autonomy and say in family matters is often contrasted with restrictive gender arrangements in the north. Since Dyson and Moore's [7] early formulation linking demographic outcomes in the two regions to gender arrangements, other studies have established the importance of gender arrangements on fertility in India. While important, gender arrangements are but one of several possible factors that have patterned fertility in India [8]. These include penetration of mass media, increasing aspirations engendered by the possibility of economic movement, and political freedoms [9]. While factors that have traditionally been associated with changes in fertility like higher literacy rates, economic change, and improvements in child mortality might have played a role, they do not explain the dramatic decline in some of the southern states. These declines point to strong local influences, like, for instance, the strong ruralurban linkages in Tamil Nadu [10] or improvements in various indicators of human development in Andhra Pradesh [11]. From the experience of fertility decline in South India, it is clear that there is no single explanation for fertility decline that applies to the southern states, but rather a combination of factors including development, diffusion, policy, and local sociopolitical contexts.

While the pathways of fertility change might have been different, the means to limit fertility has been surprisingly similar. Female sterilization continues to be the predominant and preferred method of fertility control. About one-third of currently married women had opted for sterilization; in comparison only about 4 per cent of women were using pills [12]. Even in states where fertility has declined substantially, sterilization continues to be the main contraceptive method despite recent efforts to promote reversible methods. The continuing reliance on sterilization no doubt has its origins in the 1970s when it was promoted vigorously. In terms of population growth, the use of permanent methods like sterilization might push period fertility down but in the long run result in a larger population than a policy promoting birth spacing and late marriage [13].

Another aspect of fertility change that is nearly uniform across states is the role of marriage and marital fertility. Marriage continues to be universal and relatively early in most of India. Early marriages mean that the age at first births is also relatively early (median age at first birth was 19.8 in 2005-6, NFHS-3) because contraception before first birth is uncommon. Thus even in states where fertility has declined substantially, women have their first birth when they are relatively young. The continuing prevalence of early marriage and use of terminal (permanent methods) like sterilization has led to compression of the reproductive span, with the mean reproductive span of just 4.5 years in Andhra Pradesh [14]. While both marriage age and marital fertility could influence fertility rates, changes in marital fertility have had a much stronger influence on fertility than marriage age in India [15].

Thus the Indian fertility landscape is heterogeneous in terms of trajectories of fertility patterns and the forces driving them. However, there are common elements like the prevalence of early and universal marriage and preference for terminal contraceptive methods. 


\section{Regional Aggregations}

To study regional fertility change, regions must be defined first. For a demographic study based on secondary data the level of aggregation and classification of regions is often dictated by the structure of the available data. In this paper, we classify regions based on aggregation of states into six regions-North, Central, East, Northeast, West, and South (Figure 1). Disaggregation below the state level is not possible with the data used in this analysis. In forming these broad regional classifications, we are aware that there is heterogeneity within these regions. However they are less intense than the difference between the regions.

Northern Region. The northern region comprises the states of Haryana (known for its skewed sex ratios), Himachal Pradesh (a mountainous state nestled in the Himalayas), Jammu and Kashmir (the only Muslim majority state in India), Punjab (a prosperous agricultural state), Rajasthan, and Uttaranchal (a state carved out from Uttar Pradesh in 2000). In demographic terms, fertility rates varied from 3.21 children per woman in Rajasthan to a low of 1.94 in Himachal Pradesh in 2005-2006 (NFHS-3). One common feature of many of the states in this region is the skewed sex ratios. The recently released Census 2011 provisional data show a child (0-6) sex ratio (female per 1000 males) of 830 in Haryana and 906 in Himachal Pradesh [16]. All states in the region have sex ratios below the national average. The skewed sex ratios are a manifestation underlying preference for sons, and such preference has important implications on fertility both in terms of number of children and in the decision to space births [17].

Central Region. The central region comprises the states of Chhattisgarh (a state with about one-third of the populace classified as Scheduled Tribes), Madhya Pradesh, and Uttar Pradesh (the most populous state in India with population of 199 million in 2011). The fertility in these states varied from 2.8 (Chhattisgarh) to 4.06 children per woman (Uttar Pradesh) in 2005-06 (NFHS-3). The three states in this region had the highest infant mortality rates in the country. In both Madhya Pradesh and Chhattisgarh, states with high proportion of tribal population, fertility is generally low mainly because of "delayed female marriage, relatively prolonged breast feeding and longer birth intervals, greater gender equity and female autonomy" among the tribal groups [18].

Eastern Region. The eastern region comprisies the states of Bihar (a state which consistently ranks at the bottom on various human development indicators), Jharkhand (a state that was bifurcated from Bihar in 2000), Orissa, and West Bengal (the only state in which power was held by the communist party uninterrupted from 1977 to 2011). Fertility in the last two states is considerably lower (around 2.3 children per woman) compared to the former two states (3.3 and higher) (NFHS-3). In West Bengal, fertility began to decline beginning in the 1960s and, as Basu and Amin
[19] have noted, smaller family norms diffused through all sections of the society, despite government indifference to population policies.

Northeast Region. The eight states in the region are made up of numerous tribal and caste groups and in some states a significant number of migrant Bengali populations. The region is characterized by relatively late marriages (compared to the rest of India), absence of son preference, and longer birth intervals [20]. According to the latest National Family Health Survey (NFHS) conducted in 2005-06, the fertility in the region varied from just below replacement in Sikkim to a high of 3.8 children per woman in Meghalaya.

Western Region. The three states in the region-Goa, Gujarat, and Maharashtra-have fertility rates below the national average of 2.7. Goa (with a large Christian minority population), Gujarat (a state known for its manufacturing and industrial sector), and Maharashtra (with large urban centers like Mumbai and Pune) have generally been in the forefront of human development. Also in contrast with the neighboring northern states, the status of women is higher. Jejeebhoy and Kulkarni [21] note that in Maharashtra this relatively higher status of women meant that there were no significant differences in fertility desires between men and women. This is a possible reason for relatively low fertility in the state.

Southern Region. The four states in the south, Andhra Pradesh, Karnataka, Kerala, and Tamil Nadu, have fertility rates below replacement level. Kerala was the first state to reach below-replacement fertility and this has been attributed to high level of literacy, progressive social system, and low infant mortality rates. The fertility decline in the south has not followed a single pathway. While diffusion played a key role, as Guilmoto [22] has emphasized, the diffusion was endogenous and centered on several areas in south India. There appear to be several state-specific factors from human development in Kerala to social capillarity (diffusion of ideas downwards) in Andhra Pradesh which might explain fertility decline in the south (see chapters in Guilmoto and Rajan [23]). In this descriptive paper, we focus on a narrow aspect of fertility change in India, by examining the regional trends in parity progression ratios and birth intervals over the last three decades. This paper sketches some aspects of fertility variations in the six regions and compares and contrasts the fertility histories in these six regions.

\section{Data and Methods}

In this study, we use data from three rounds of the National Family Health Survey of India (NFHS). NFHS are nationally representative sample surveys which collect-among a large number of other demographic and health-related questionscomplete birth history data for all women aged 15-49. These datasets can be freely downloaded on request at http://www.measuredhs.com. 

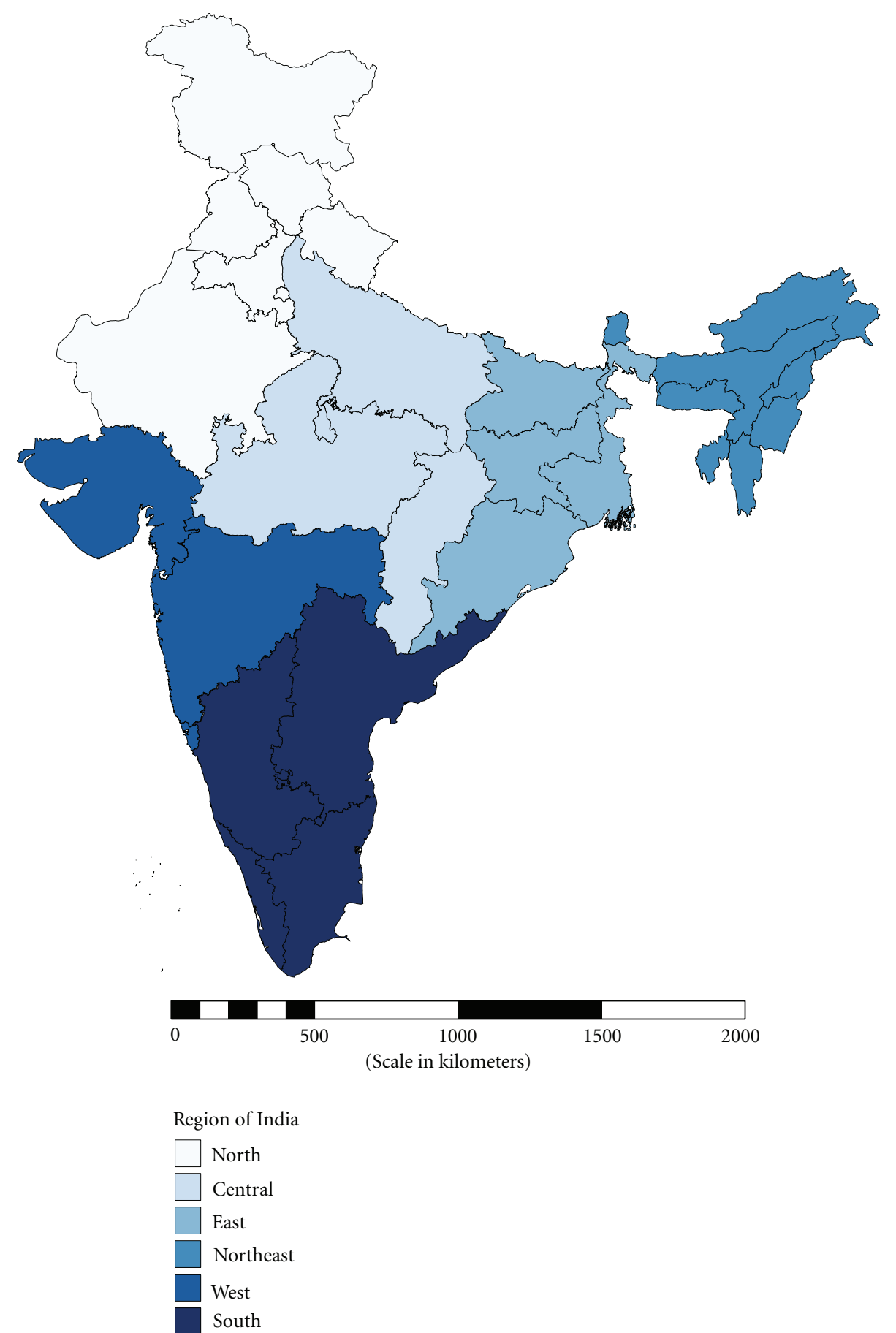

Figure 1: Regions of India. Note. See text for the definition of the regions.

The first NFHS (NFHS-1) was conducted between April 1992 and September 1993 in 25 states. (Sikkim was not included in NFHS-1.) For rural areas, the list of villages from the 1981 Census of India served as the sample frame in all states, except for Assam, Delhi, and Punjab where the 1991 Census data were used. For urban areas, the 1991 Census of India served as sampling frame. At the national level, 89,777 ever-married women aged 13-49 were interviewed and the individual response rate reached 96.1 percent. At the state level, the sample size ranged from 882 women in Arunachal Pradesh (Northeast) to 11,438 women in Uttar Pradesh (Central), with most of the larger states having a sample of above 3,500. The individual response rate ranged from 91 percent in Arunachal Pradesh to almost 100 percent in Nagaland, with a rate of more than 95 percent in the majority of the larger states. As the main variable used in this study, information collected in the birth history (especially the date of birth) was exceptionally complete in the NFHS-1, with 
about 97 percent of all the children (living and dead) having a complete birth date. Among the 187,405 births that have occurred in the 15 years before NFHS-1, 2.38 percent had missing information on the month of birth and for only 0.07 percent the month and the year of birth were missing [24].

Data collection for the second NFHS (NFHS-2) extended between November 1998 and December 1999 in 26 states. (Due to local problems, fieldwork in Tripura was delayed and this state is not included in the NFHS-2 report [25], but appears in the microdata.) For rural areas, a stratified sampling frame based on the 1991 Census list of villages was used. The sampling frame in urban areas was similar to the one followed in rural areas. At national level, 89,199 ever-married women aged 15-49 were interviewed and the individual response rate reached 95.5 percent. At state level, the sample size ranged from 818 in Nagaland (Northeast) to 9,292 in Uttar Pradesh (Central). The individual response rate ranged from 90.8 percent in Delhi (North) to 99.7 percent in Tamil Nadu (South). Most of the larger states had an individual response rate of 93 percent and more. Overall, children's birth dates collected in birth history were completed in 94.6 percent of the case. For the birth in the 15 years preceding the survey, nearly 4 percent (3.76) had missing month of birth and 0.12 percent had month and year of birth missing [25]. Compared to NFHS-1, the data quality of NFHS-2 is slightly lower.

The third NFHS (NFHS-3) was conducted between November 2005 and August 2006 in 29 states. (In 2000, Uttararkhand, Chhattisgarh and Jharkhand were carved from Uttar Pradesh, Madhya Pradesh and Bihar resp.) The 2001 Census list of villages, in rural areas, and list of wards, in urban areas, were used as sampling frame. Unlike in NFHS1 and NFHS-2 that interviewed only ever-married women, NFHS-3 collected data on all women. 124,385 women aged 15-49 were interviewed and the individual response rate reached 94.5 percent. The sample size varies across states between 1,647 women in Arunachal Pradesh (Northeast) and 12,183 in Uttar Pradesh (Central). The individual response rate varied from 89.5 in Maharashtra (West) to 98.8 in Madhya Pradesh (Central). Overall, 97.7 percent of the children had a complete birth date. Among the births that have occurred during the 15 years preceding the survey, 1.23 percent had a missing month of birth and 0.17 percent missing month and year of birth. Compared to the two previous NFHSs, while the overall individual response rate was the lowest in the NFHS-3, the data quality was the higher in NFHS-3.

To examine the fertility transition at regional level in India, we use the period parity progressions ratios (PPPRs). Period parity progression ratios (PPPRs) were originally proposed by Feeney [26], Feeney and Yu [27], and Bhrolcháin [28]. PPPRs can potentially be applied to a large number of (retrospective survey) data. Yet, PPPRs are problematic because of censoring and selection [29]. To account for the censoring problem, Hinde [29] proposed a new procedure for computing PPPRs. To distinguish the latter application from its "original" formulation, and following Pullum [30], the expression "synthetic parity progression ratios," and the acronym SPPRs are used. Parity progression ratios are useful to understand fertility-limiting behaviors since a woman's decision to have an additional child is very often likely to be based on the number of children she already has and the time elapsed since her previous birth (i.e., Coale's conventional view of the fertility decline as a parity-dependent behavior) than on her age alone.

To compute SPPRs, women giving birth in a given year are followed "backward" in time until the date of their previous child, allowing thus to address the problem of censoring. The calculation of the SPPRs is based "on the $(j+1)$ th births occurring in a particular year to the women who had their $j$ th births in a range of previous year" ([29], emphasis added). The progression from the $j$ th to the $(j+$ 1)th birth, $a_{j}$, can be expressed as.

$$
a_{j}=1-\left(1-q_{0}\right) \cdot\left(1-q_{1}\right) \cdot\left(1-q_{2}\right), \ldots,
$$

where the series of $q_{x}$ are proportions computed as the number of women who had their $j$ th birth in the $x$ th year before the current year and their $(j+1)$ th birth in the current year, divided by the total numbers of women who had a $j$ th birth in the $x$ th year before the current year minus the number of these women who have already had their $(j+1)$ th birth before the start of the current year. To compute these ratios, number of years must be considered in order to go back in time as far as necessary to capture the vast majority of women who will go on to have another child. As birth intervals of more than ten years are rare in most populations, a good rule of thumb is to go ten years back in the computation of the SPPRs [23]. For the progression to the first birth, because childbearing at very young ages occurs in India, the year a woman reached her 10th birthday was selected as the preceding event and a period of 25 years back in time was selected in the computation of the SPPRs in order to include in the numerator all the women who will eventually go on to have a first child. The SPPR can be interpreted as the probability that a woman of parity $i$ will have to move to parity $i+j$ if she maintains the fertility level observed during the given year throughout her reproductive life.

Together with the SPPRs, the mean birth intervals by single year are used to study the changes in reproductive and family-building behaviors (spacing or stopping patterns). The mean birth intervals are calculated based on women who had their previous birth within a period of ten years before a given year.

We estimate the fertility decline for each region in India using the average number of children ever born in a given year $t$, that is, the synthetic lifetime average parity, $P_{t}$,

$$
P_{t}=\frac{\left[\left(\sum_{i=0}^{j} N_{i} \cdot P_{i}\right)+N_{k} \cdot P_{k}\right]}{100},
$$

where $i$ to $j$ indicate the completed parities; $k$ indicates the open-ended parity group (here, women with $6+$ children). The average number of children observed among those women $\left(N_{k}\right)$ in the survey dataset is taken as an estimate of the number of children of women in the open-ended parity group. 
Finally, we determine the contribution of the changes of each birth order to the overall decline in fertility by decomposing the synthetic lifetime average parity in a given year $t, P_{t}$, into its parity-specific constituents.

Women with multiple births, inconsistent birth histories, and births intervals of less than 8 months were excluded of the computation of SPPRs. In order to obtain completed annual birth histories, SPPRs were computed for a 15-year period before each survey, excluding the survey years.

\section{Results}

The results are organized under two broad sections: (a) changes in average lifetime parity and decomposition of fertility decline; (b) changes in synthetic parity progression ratios and birth intervals.

Changes in average parity between 1977 and 2004 for the six regions are presented in Figure 2. Around 1977, average parity in all the regions, except the central region, was about 5 or lower. In the south and the west average parity was just below 4. Despite differences in the 1970s, average parity declined in all regions, though at different rates in different regions. By the mid-2000s, average parity had declined to below two in the south and west, the two regions that had the lowest rates in the 1970s. In the central region average parity remained high at just below 3.5 . In the remaining three regions, average parity had declined to around 2.5 by 2004 .

Average lifetime parities charted in Figure 2 are based on three rounds of survey data and the average parities for years 1984 and beyond can be calculated from more than one round of data. The overlap of the estimates of average parity from the various rounds is a good indication of data quality. As seen in Figure 2, the degree to which the estimates overlap varies by region. In the south and west, there is considerable agreement between the various rounds of data, while other regions show sharp declines in average parity in the five or so years preceding the survey. Such a tendency is not unique to Indian data and is attributed to age displacement in one or both surveys. Pullum [31] mentions two main reasons for such a displacement. First, interviewers might have placed some children above the upper age limit to avoid asking detailed questions from the child (ages 0-5) module. Second, the displacement might be because women in some cultures tend to transfer recent births to an earlier time. Though the results presented do not allow us to infer the type of age displacement and to identify if one or both surveys were affected by it, it is clear that the data from the central region are much more affected than other regions.

Decomposition of fertility decline presented in Figure 3 helps us gauge the relative contribution of declines at various parities to overall fertility decline. In all regions, with the exception of northeast, contribution of changes in first birth to overall fertility decline has been minimal. This indicates that having at least one child still continues to be the norm. In the northeast reduction in first births has contributed to about one-child decline in fertility between 1995 and 2003. This perhaps reflects changes in timing of marriage, and consequently changes in timing of first births, rather than decline in firth births. In all regions without exception, transition to second birth closely follows the trend of first birth. Similar to first birth, the changes in transition to second birth have contributed very little to overall fertility decline over the last three decades. Even in regions like the south that have low fertility, reduction in second birth has not been an important factor in the fertility decline. Thus, it appears that the two-child norm is pervasive and persistent in all regions.

The major reason for decline in fertility rates, as shown by the decomposition analyses, is due to the reduction in 3rd- and higher-order births. Starting in the early 1980s in the south and west fewer and fewer women transitioned from second to the third birth, and this contributed to the rapid decline in fertility rates. For women who had a third birth, fewer of them transitioned to fourth- and higher-order births. In the regions with continuing high fertility, like the central and northern regions, while transition to third birth has been important, declines in fourth and higher births have contributed significantly to the overall fertility decline. The findings from the decomposition analyses are corroborated by the synthetic parity progression ratios presented in Figure 4. Transition to first birth has remained fairly stable and high over the period 1977-2004 in most regions with the exception of northeast and to a lesser extent in the western region. In the northeast, data from the latest round show a steep decline in the transition to first birth reaching a low of around 70 percent in 2002 . While this trend could potentially be affected by postponement-that reduces artificially and momentarily the proportion of women having a first birthdata quality also contributes towards explaining this recent trend. The progression to second birth is uniformly high across all the six regions ranging from around 85 percent in the south and west to around 95 percent in the central region. Regional differences in parity progression ratios are apparent beginning with the transition to third birth. While in the south less than 40 percent of women who had a second birth went on to have a third birth, more than 70 percent of women did so in the central region. It is clear from the charts that in all regions the percent of women transitioning to 3rdand higher-order births has declined.

Birth intervals presented in Figure 5 show a general trend of lengthening intervals. In all regions, the interval between age 10 and the first birth has increased, reaching around 115 to 130 months, with the eastern region having the shortest and the northern region the longest birth interval. Much of the changes in the first birth interval reflect changes in marriage age. In the 2000s, the second birth interval averaged around 3 years in most regions, with the central region having the shortest interval. While the estimates of third- and higher-order birth intervals indicate lengthening of the intervals, the estimates, especially from fourth and higher birth interval, are erratic for some regions. Smaller sample size for higher-order births could be a reason for this erratic pattern. But, they also point to potential data quality issues. The degree of overlap in the estimates from the three rounds varies for different regions and for different intervals. The estimates for some regions exhibit a "v" shaped pattern suggesting a decrease in birth intervals 
Children per woman

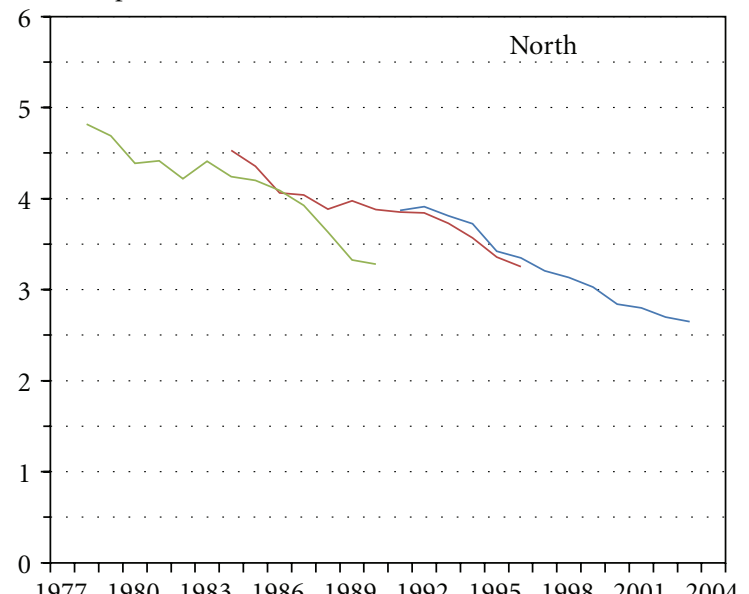

$\begin{array}{llllllllll}1977 & 1980 & 1983 & 1986 & 1989 & 1992 & 1995 & 1998 & 2001 & 2004\end{array}$

Children per woman

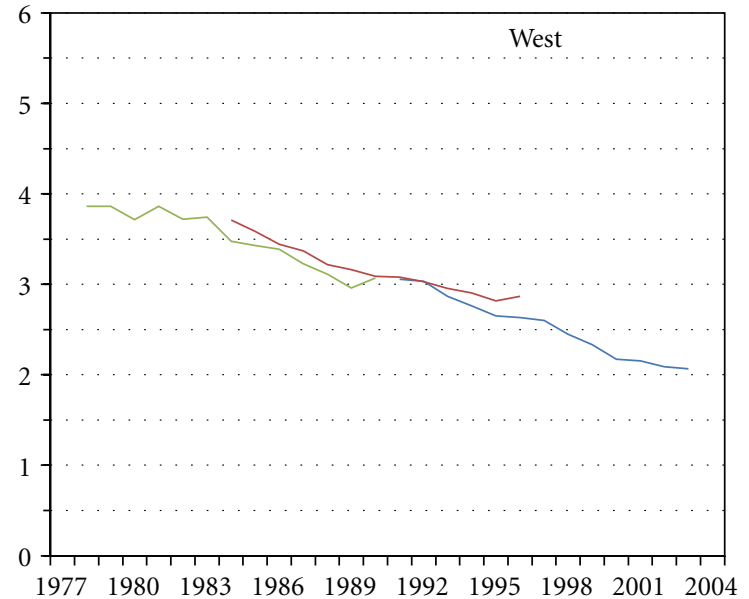

Children per woman

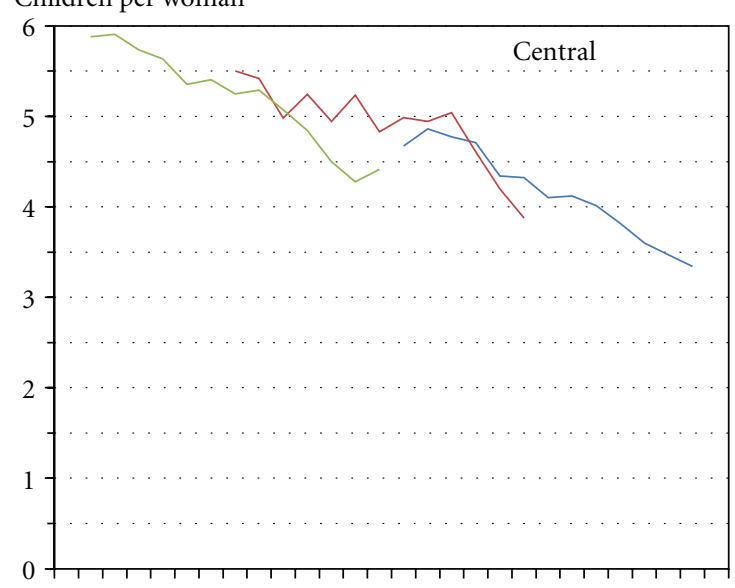

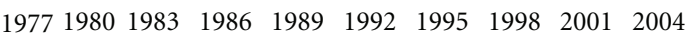

Children per woman

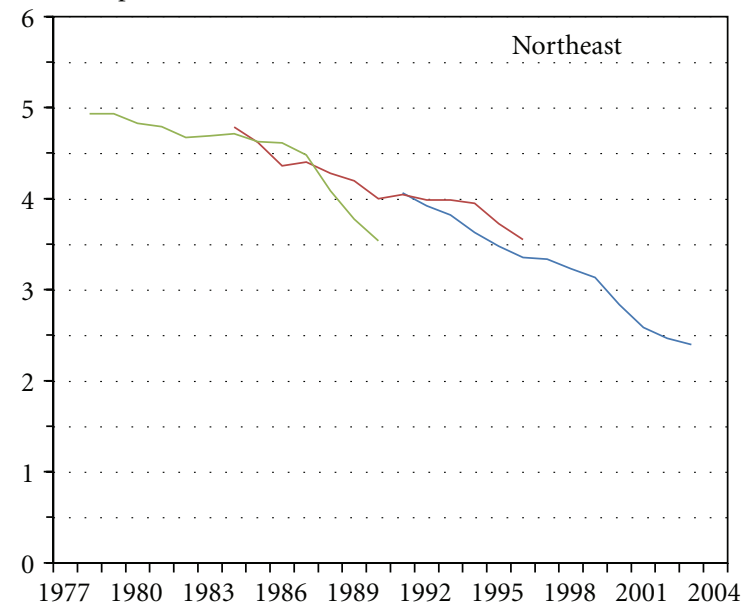

Children per woman

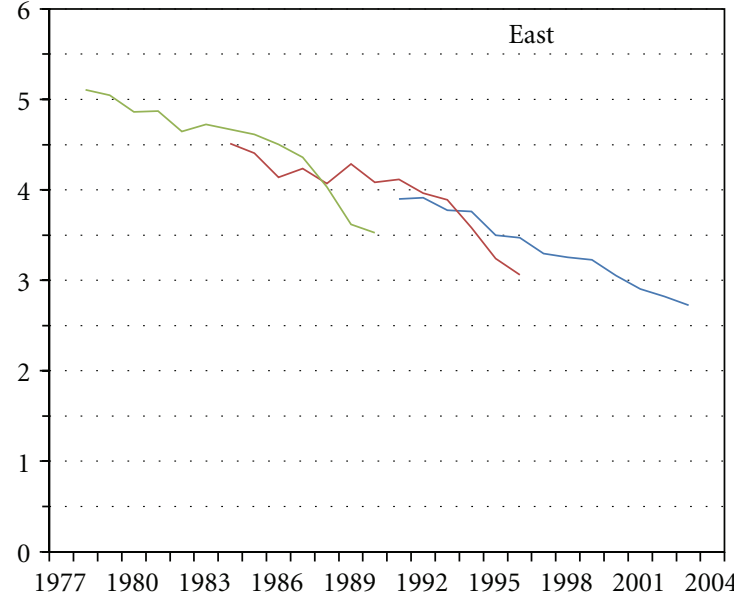

Children per woman

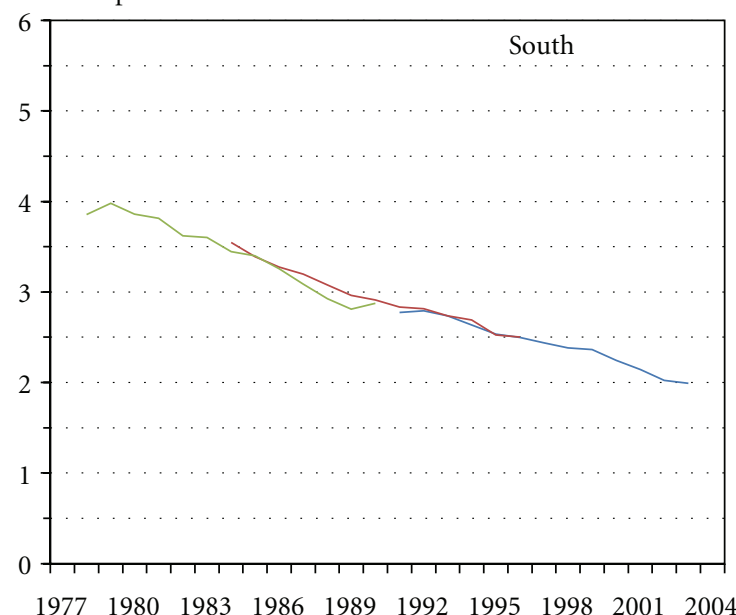

Average parity 2005-06NFHS

- Average parity 1998-99NFHS
Average parity 1992-93NFHS

- Average parity 1998-99NFHS

— Average parity 1998-99NFHS

_ Average parity 1992-93NFHS

FIGURE 2: Average lifetime parity (three-year moving average) by region, India, 1977-2004. 
Children per woman

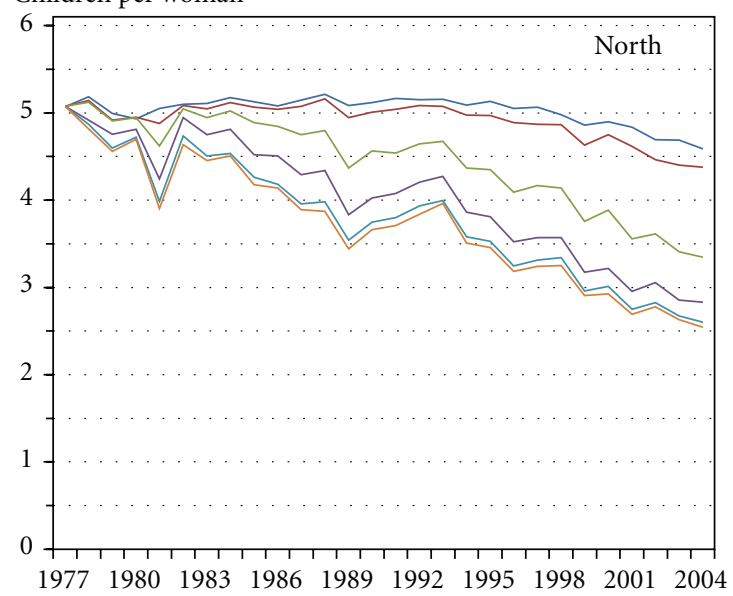

Children per woman

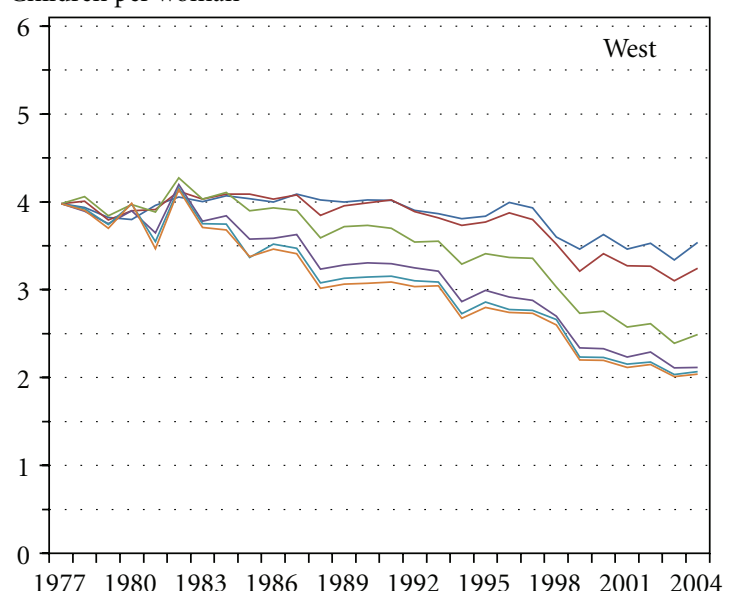

$\begin{array}{llllllllll}1977 & 1980 & 1983 & 1986 & 1989 & 1992 & 1995 & 1998 & 2001 & 2004\end{array}$

Children per woman

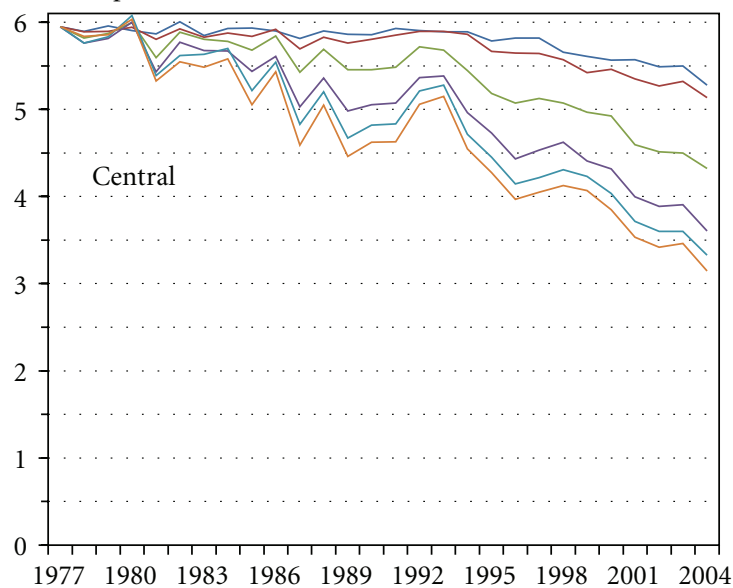

$\begin{array}{llllllllll}1977 & 1980 & 1983 & 1986 & 1989 & 1992 & 1995 & 1998 & 2001 & 2004\end{array}$

- From age 10 to 1 st birth

— From 1 st to 2 nd birth

- From 2 nd to 3 rd birth

— From 3rd to 4 th birth

— From 4 th to 5 th birth

_ From 5th to 6th birth
Children per woman

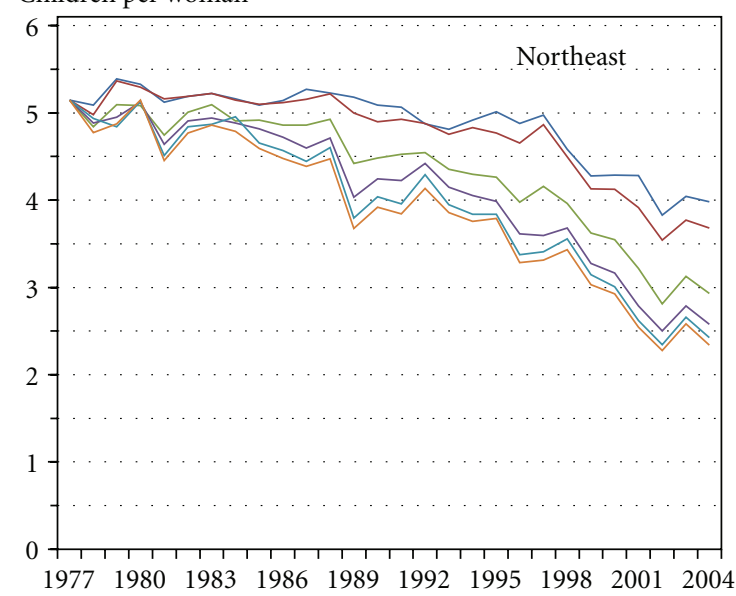

Children per woman

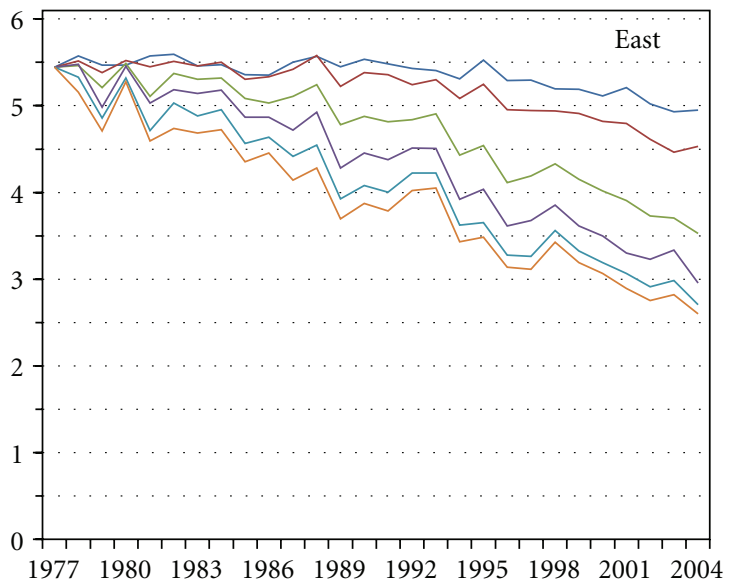

Children per woman

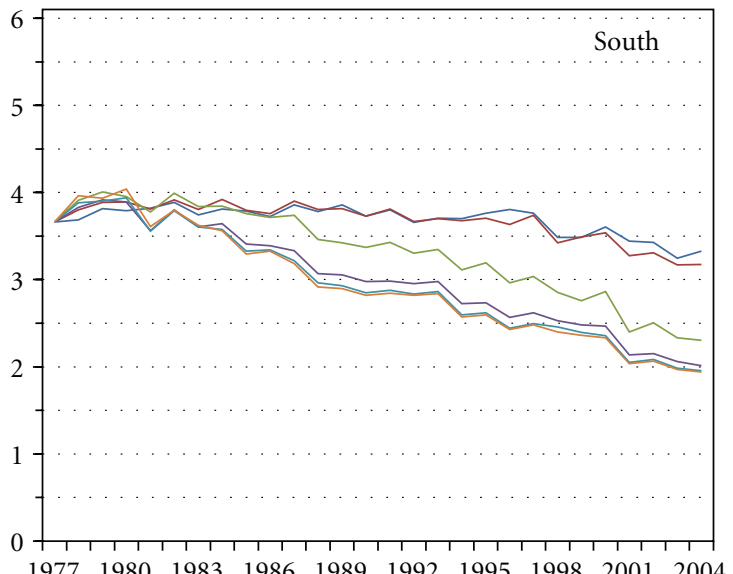

$\begin{array}{llllllllll}1977 & 1980 & 1983 & 1986 & 1989 & 1992 & 1995 & 1998 & 2001 & 2004\end{array}$

- From age 10 to 1 st birth

— From 1st to 2nd birth

- From 2nd to 3rd birth

— From 3rd to 4 th birth

— From 4th to 5 th birth

From 5th to 6th birth

FIGURE 3: Decomposition of fertility decline by progression to each successive birth by region, India, 1977-2004. 

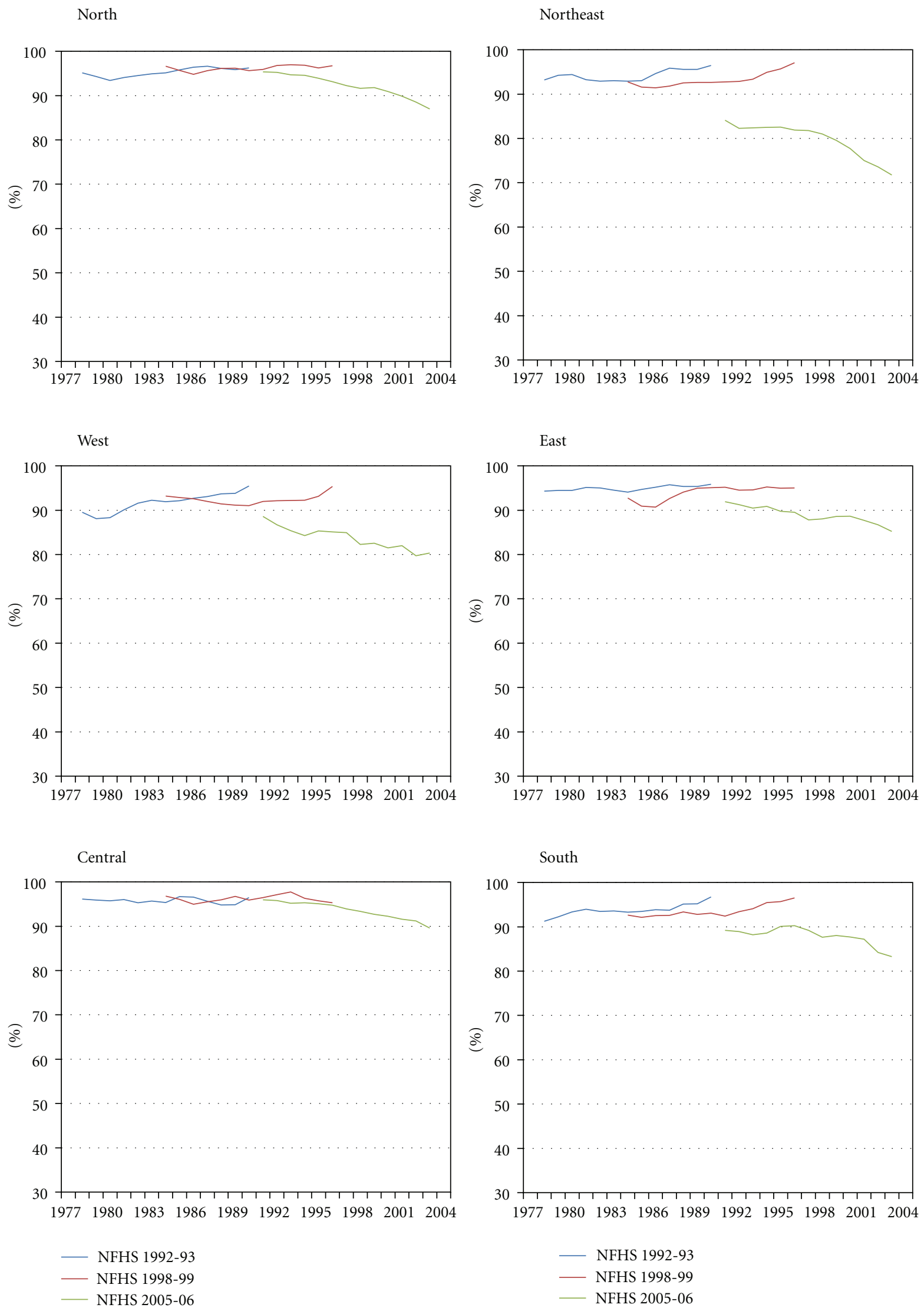

(a) Transition from age 10 to 1st birth (three-year moving average)

Figure 4: Continued. 
North
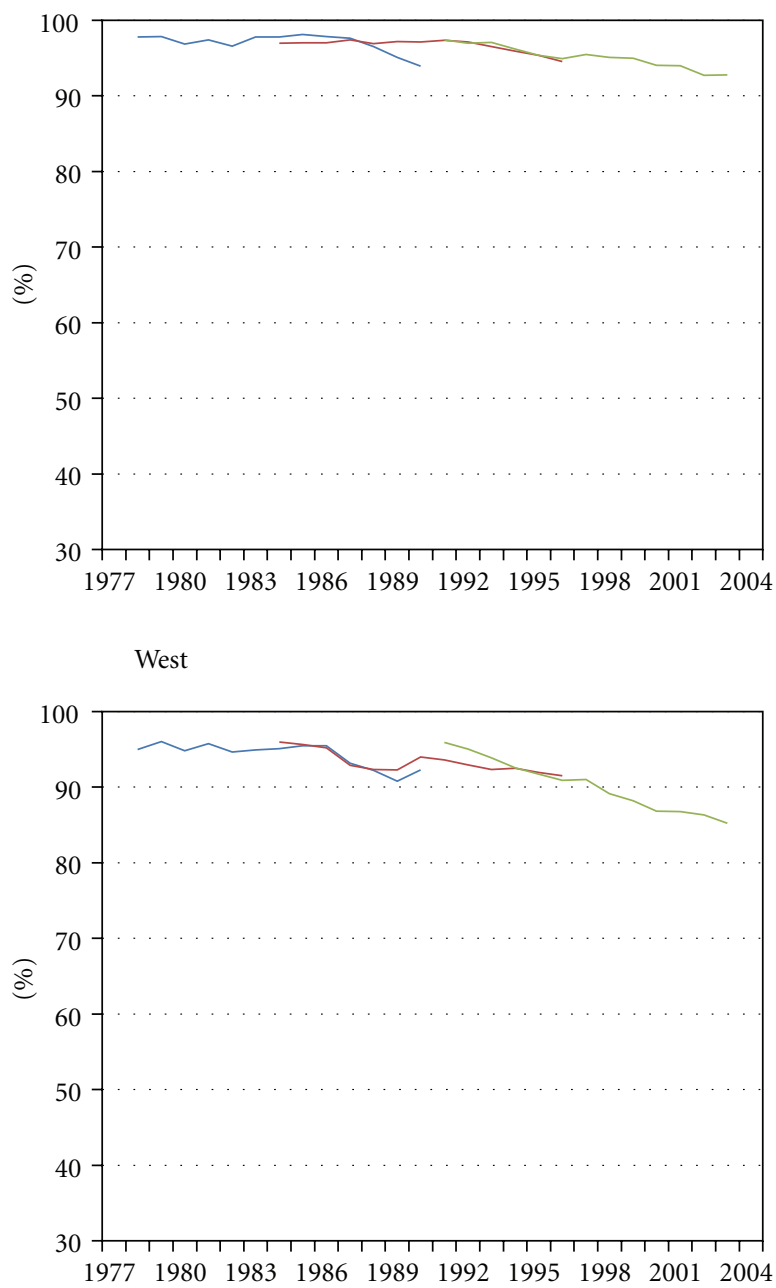

Central

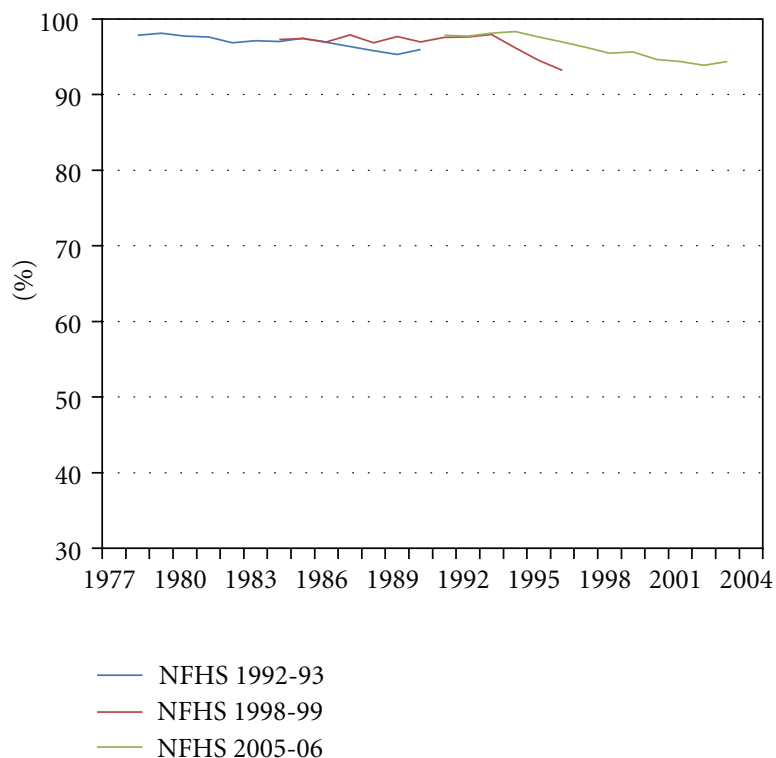

Northeast
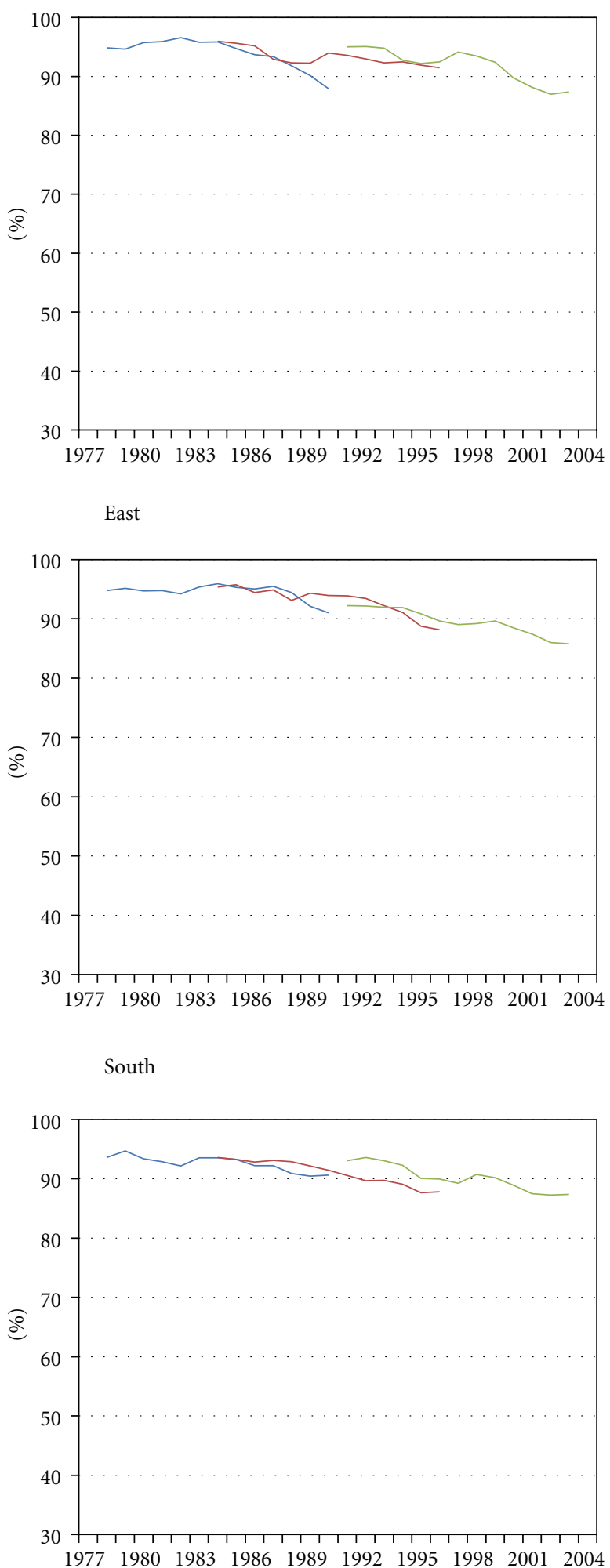

— NFHS 1992-93

— NFHS 1998-99

— NFHS 2005-06

(b) Transition from 1st birth to 2nd birth (three-year moving average)

Figure 4: Continued. 

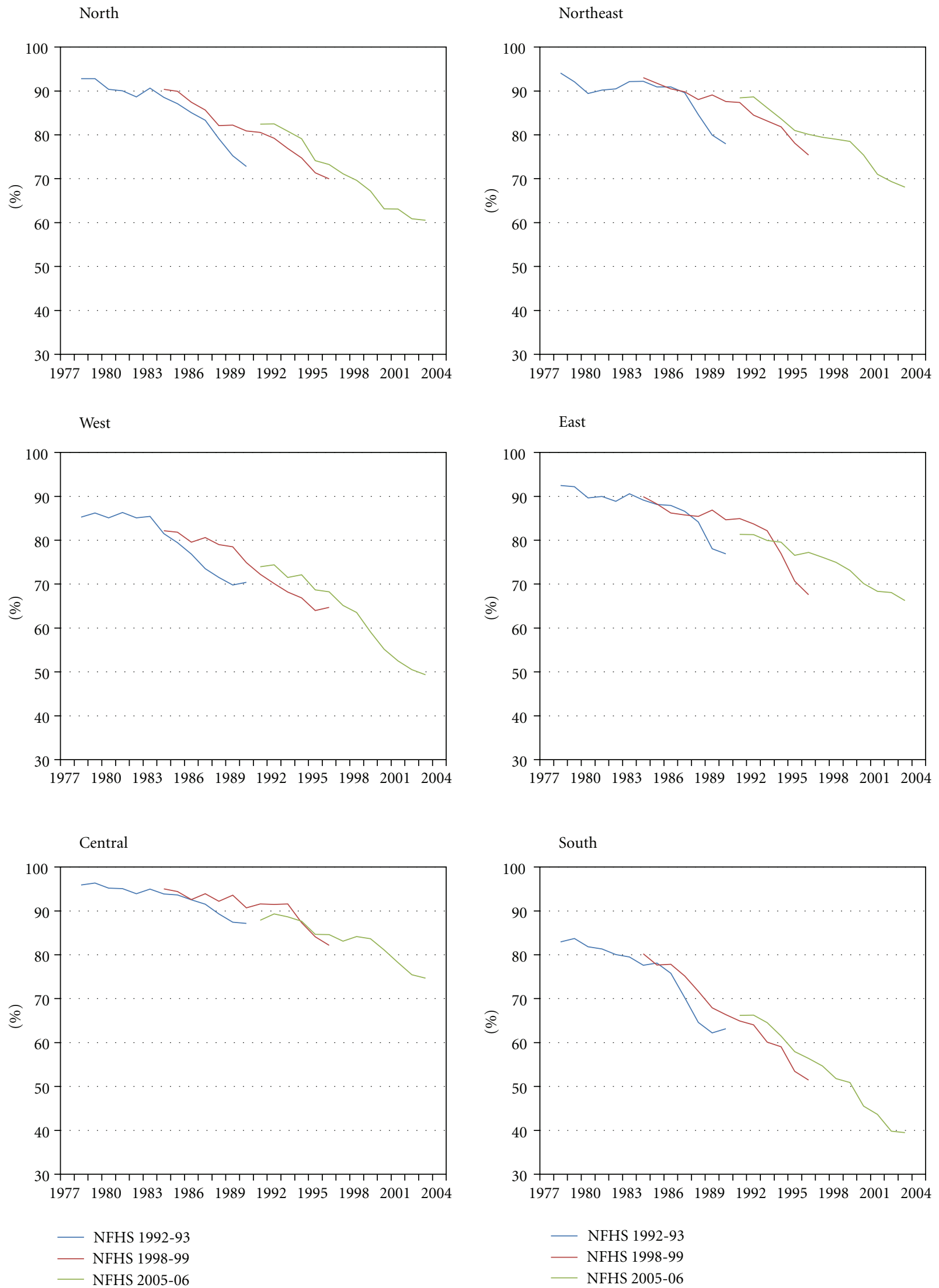

(c) Transition from 2nd birth to 3rd birth (three-year moving average)

Figure 4: Continued. 

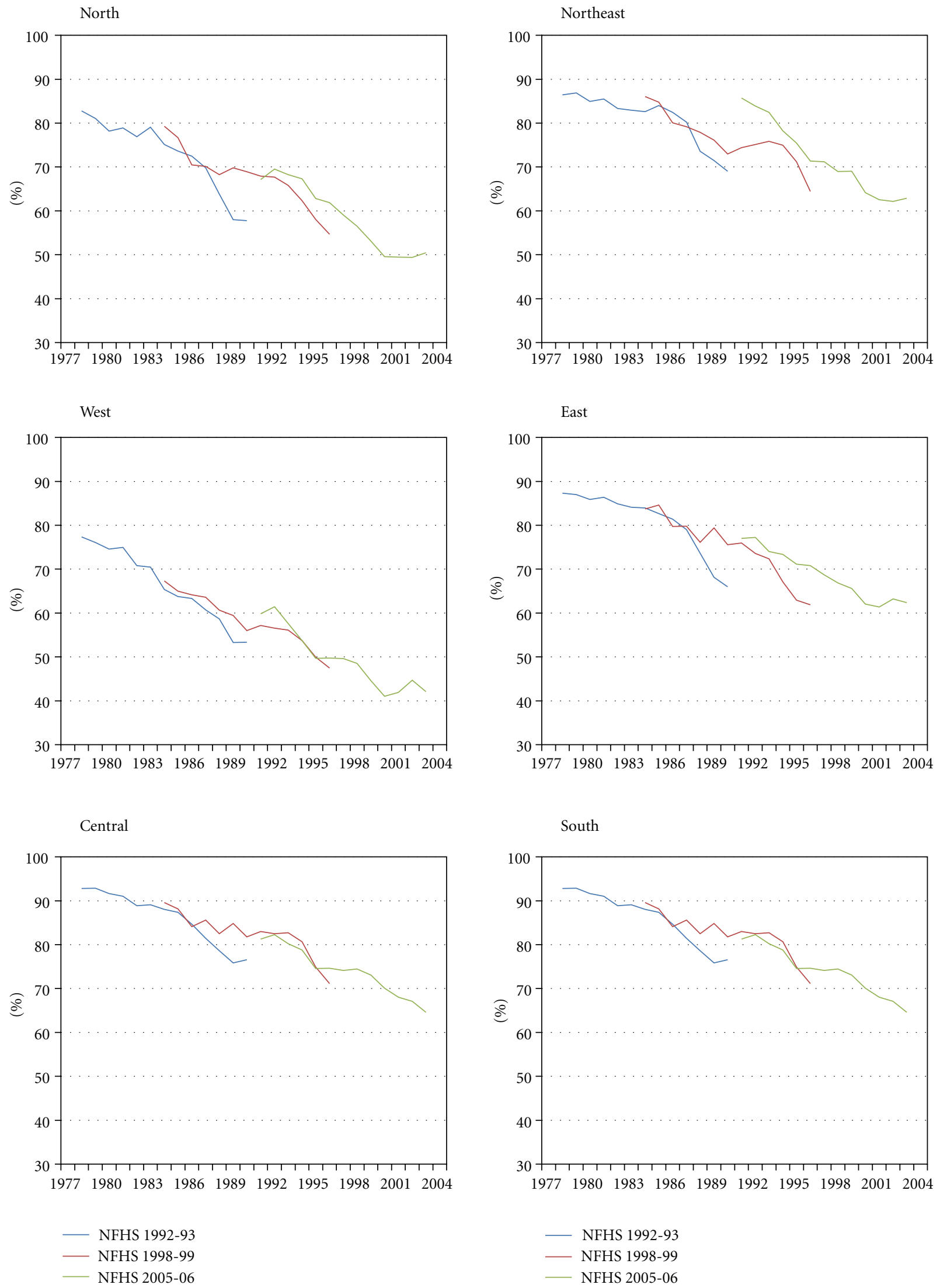

(d) Transition from 3rd to 4th birth (three-year moving average)

FIgure 4: Continued. 

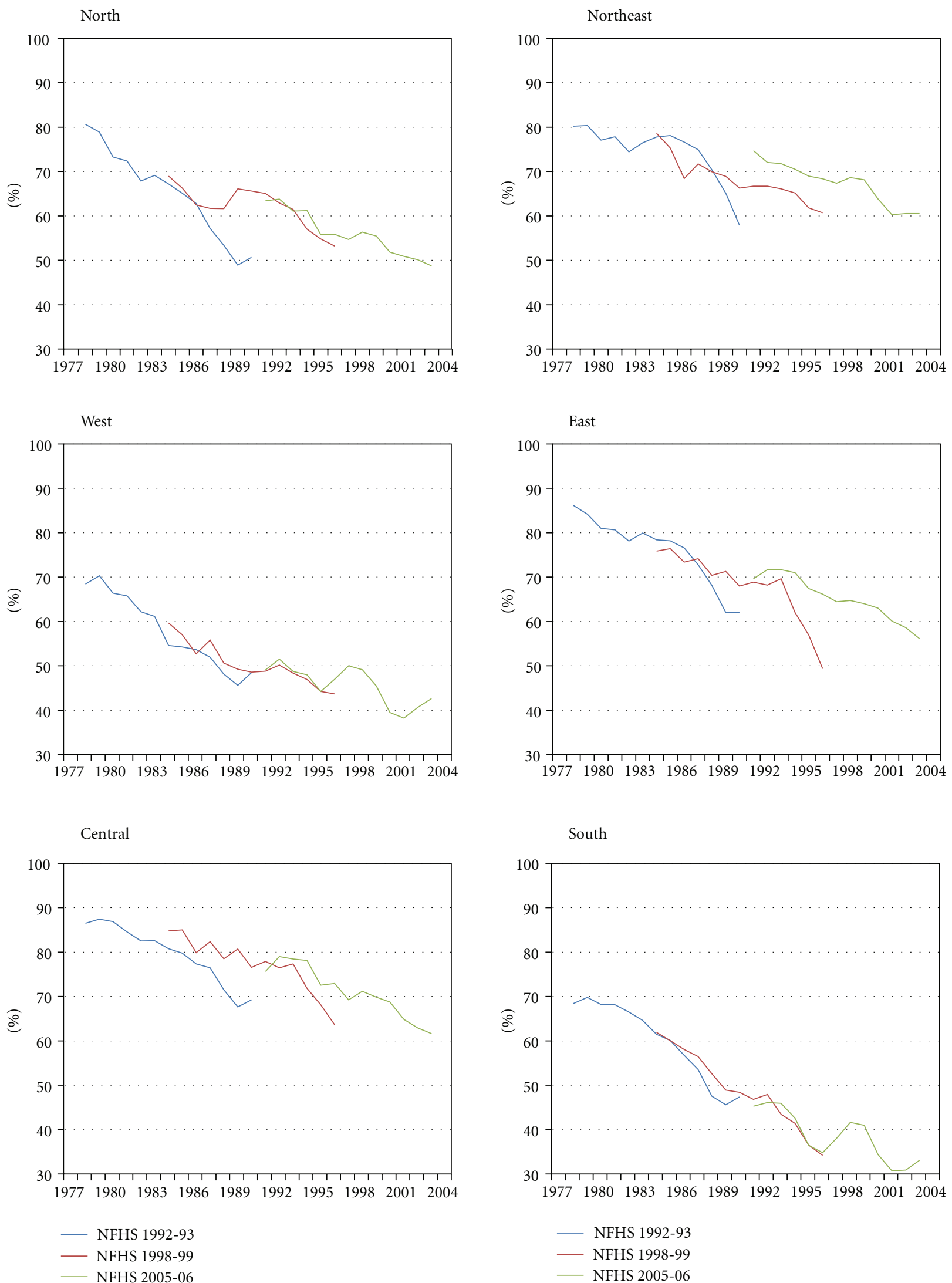

(e) Transition from 4 th to 5 th birth (three-year moving average)

FIGURE 4: Synthetic parity progression ratios by region, India, 1977-2004. 
North

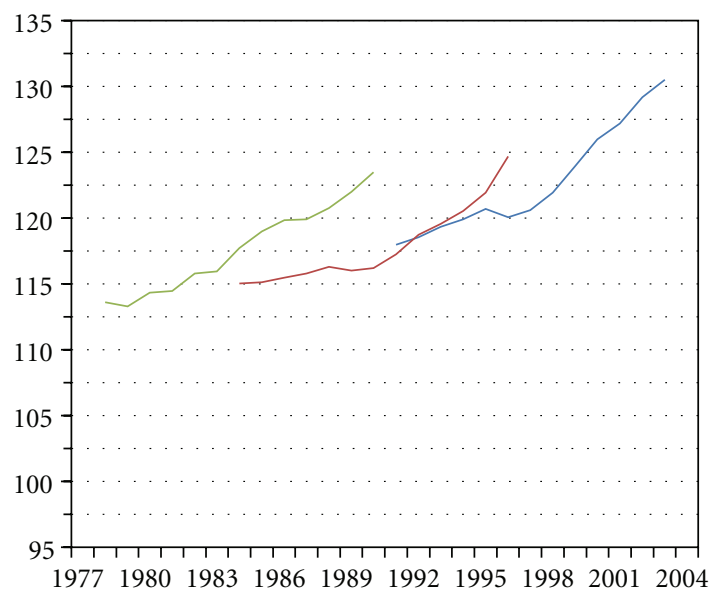

West

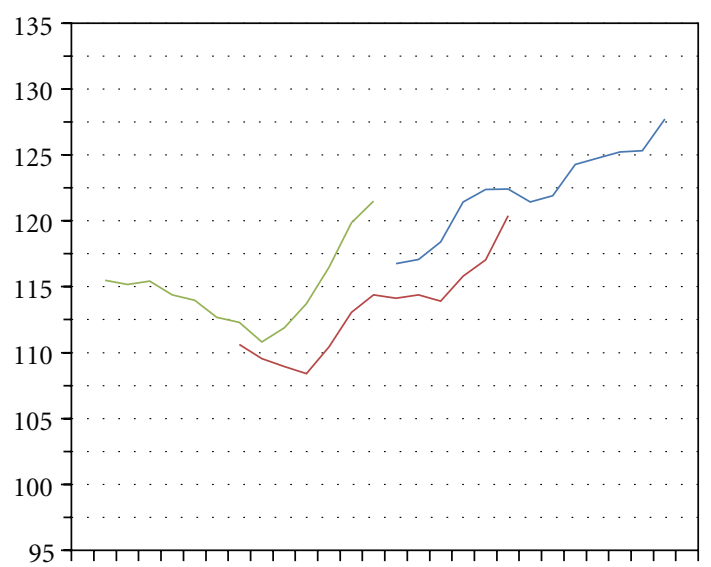

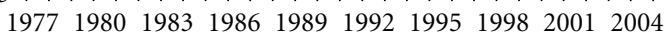

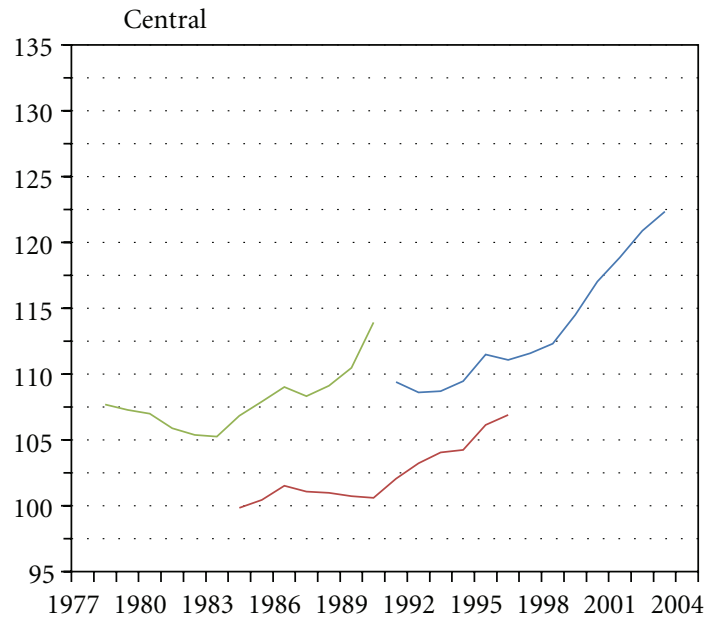

\begin{tabular}{l}
- NFHS 2005-06 \\
NFHS 1998-99 \\
\hline
\end{tabular}
Northeast

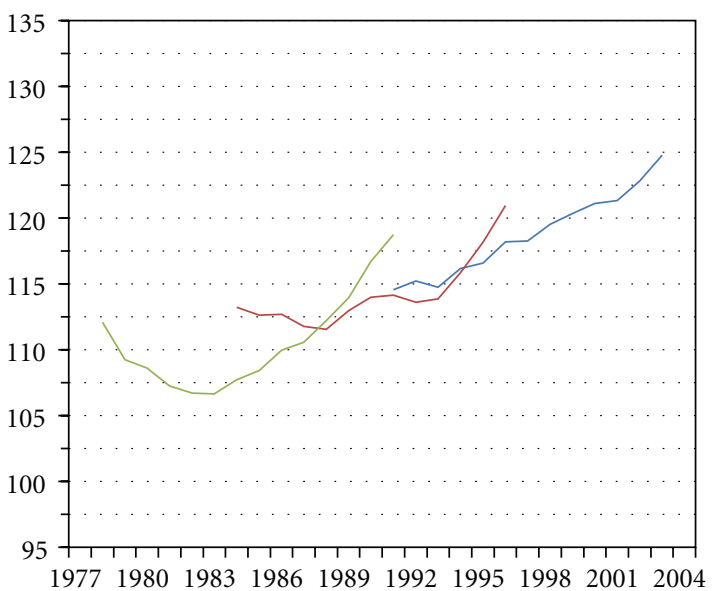

East

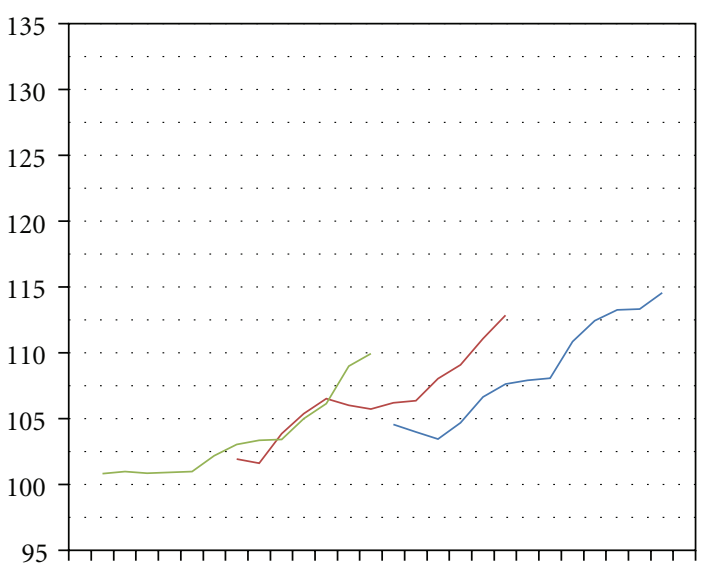

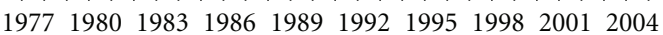

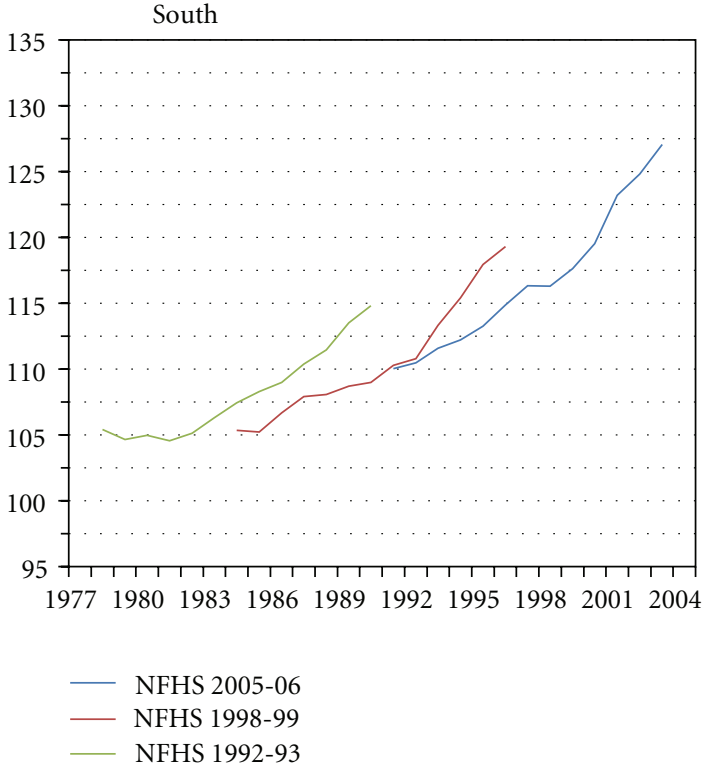

(a) Mean first birth interval (age 10 to first birth) in months

Figure 5: Continued. 

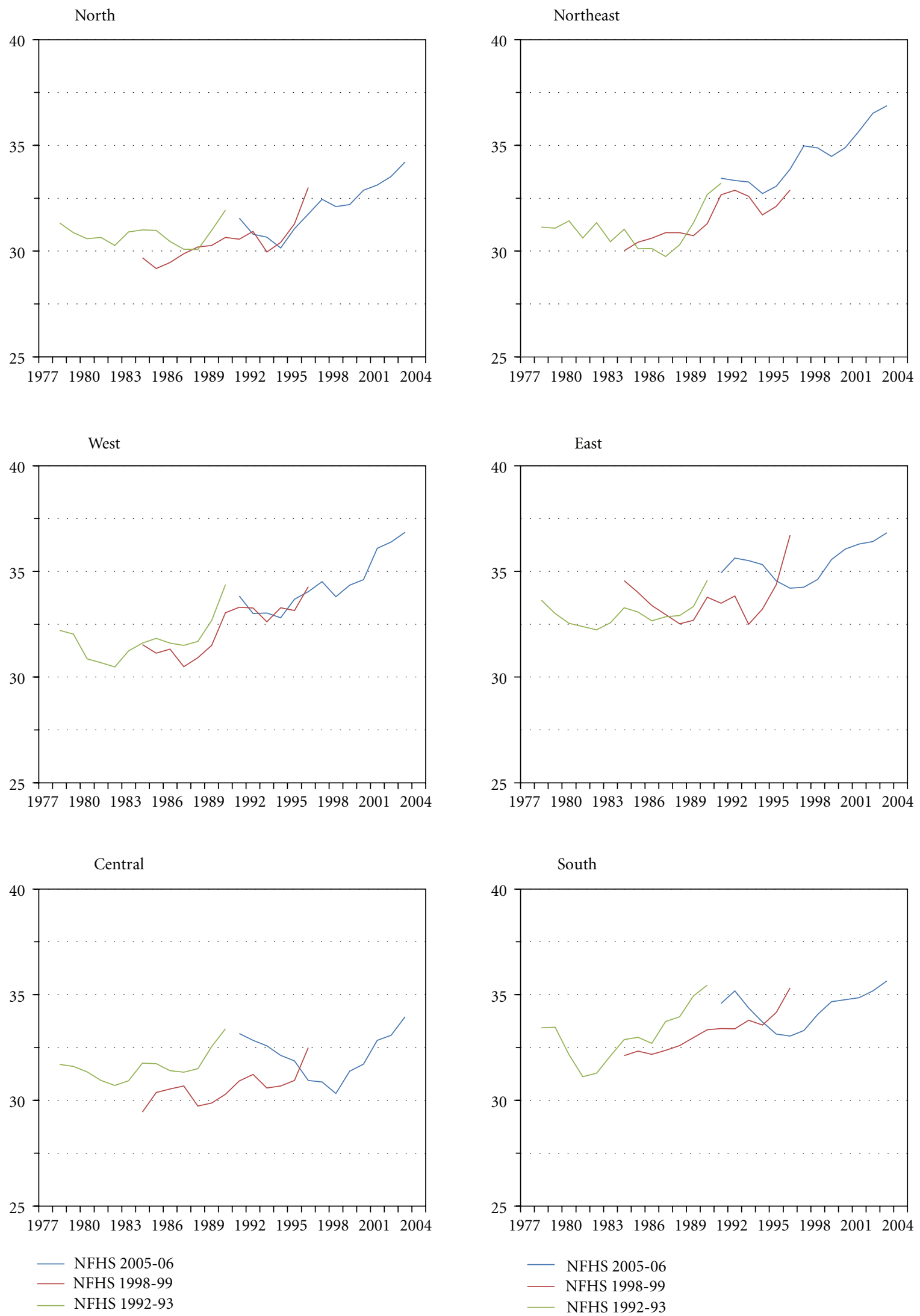

(b) Mean second birth interval in months

FIgURE 5: Continued. 

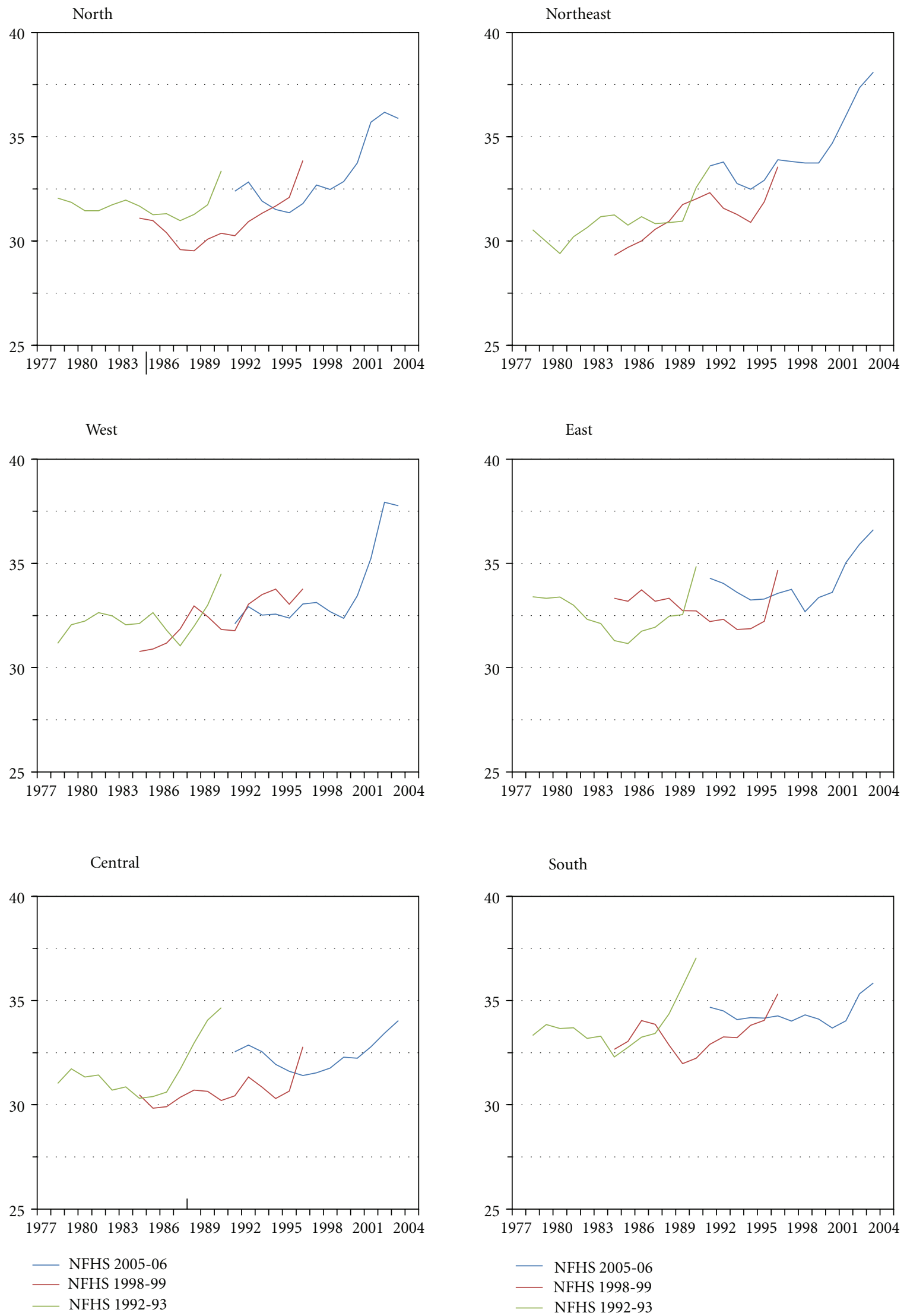

(c) Mean third birth interval in months

Figure 5: Continued. 

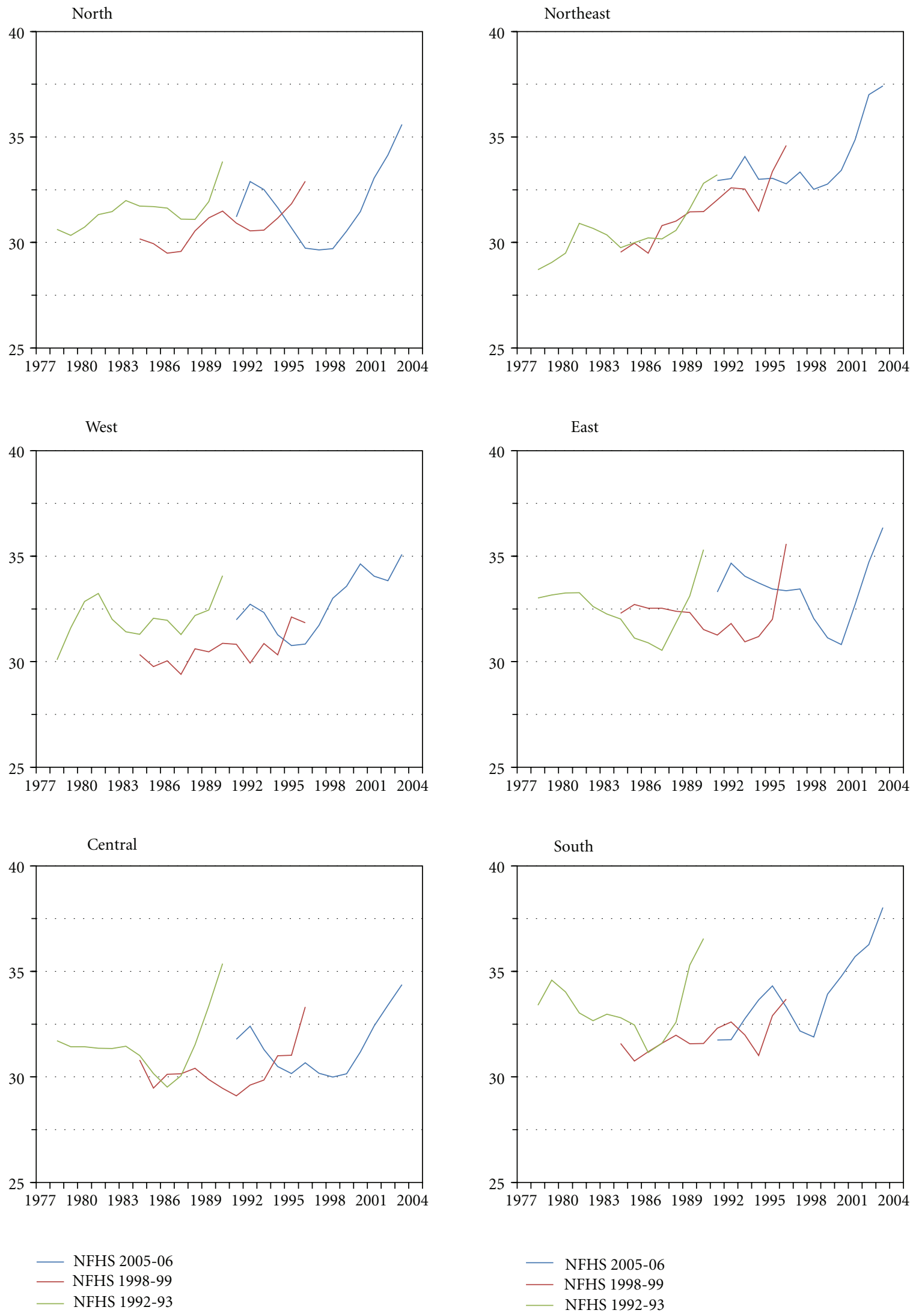

(d) Mean fourth birth interval in months

FIgURE 5: Continued. 

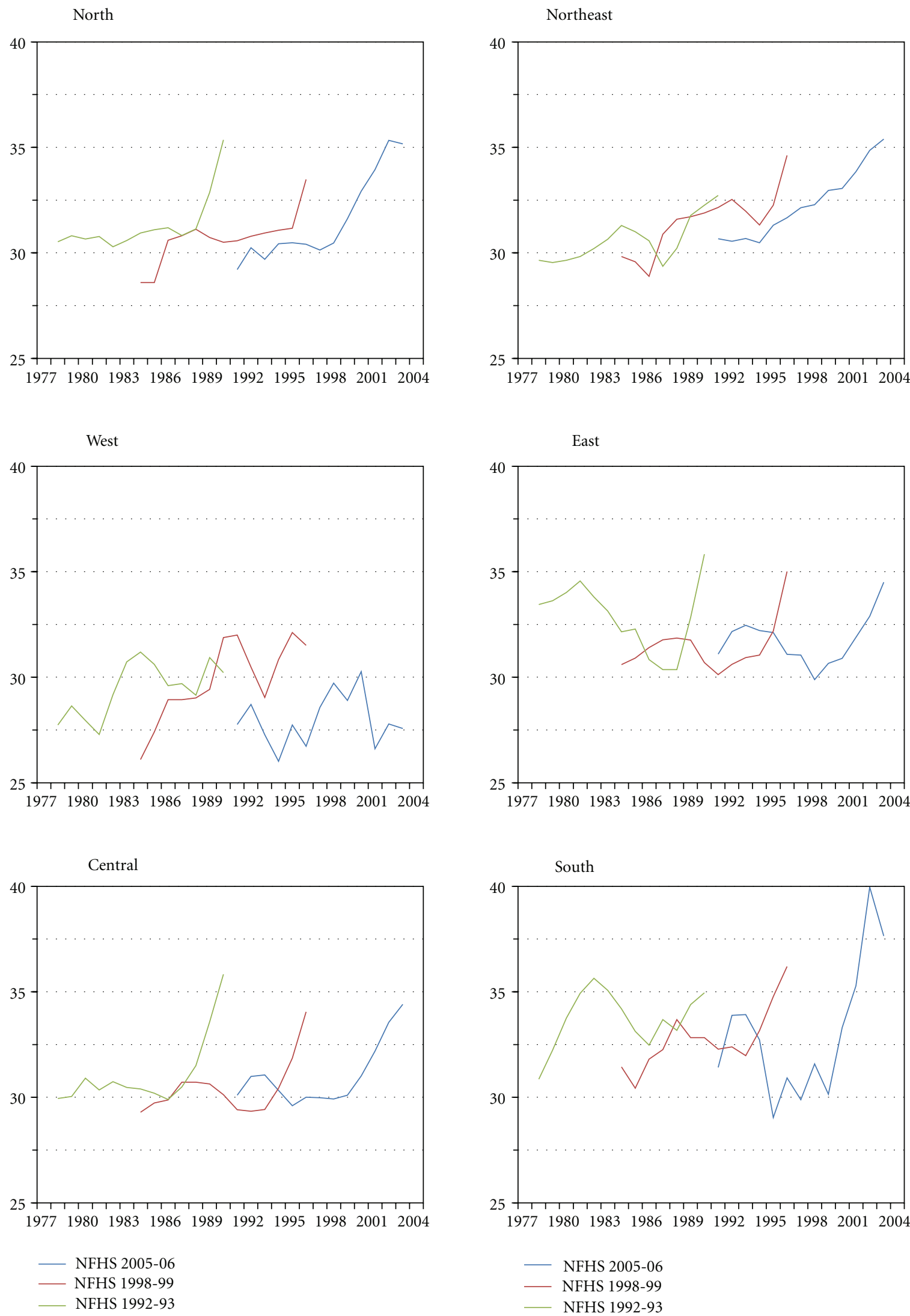

(e) Mean fifth birth interval in months

FIgURE 5: Mean birth intervals (in months) by region, India, 1977-2004. 
followed by an increase. As discussed earlier, this perhaps reflects displacement of recent births to earlier times. While the shifting of the most recent births backwards in time explains the recent increase of the mean birth intervals, the displacement of the early births of older women-these births are likely to have occurred further back in time and women may not recall the precise time of these birth-could have contributed to artificially reducing the birth intervals [32].

\section{Conclusion}

The recently concluded Indian census put the population of India at 1.21 billion in 2011. While the population growth rates have been declining since the 1970s, for the first time since independence the absolute number of people added to the population between 2001 and 2011 is lower than the previous (1991-2001) intercensal period [33]. The decline in absolute numbers is to be expected as fertility has been declining over the last forty years. As the results presented in this paper show, average lifetime parity has declined in all six regions from the level seen in the late 1970s. Though different regions started at different levels in the 1970s and the pace of the decline has not been uniform, it is expected that fertility in all regions and the national fertility would reach replacement level by mid-2020 [34]. However, due to population momentum, the national population is expected to increase to over 1.7 billion before stabilizing [35].

The results presented in this paper reveal both differences and similarities in various aspects of regional fertility patterns in India. There are clear regional differences when it comes to transition to 3rd- and higher-order births. While majority of women in high-fertility regions transition to 4 th and higher births, this is not the case in low-fertility regions like the south. Given the trends in the last few decades, it seems reasonable to expect that the fertility would continue to decline in the regions with high fertility. Since much of the population growth in India is expected to come from high fertility regions, the speed at which fertility declines in these regions will ultimately determine population growth rates at the national level.

Much of the decline in fertility is due to reduction in 3rd- and higher-order births. From the decomposition analyses, it is clear that in all regions (with exception of the northeast) declines in first and second birth have contributed little to the decline in overall fertility. With nearly universal marriage, it is not surprising that the first birth rates have not declined. This is in contrast with some countries in East and Southeast Asia where marriage delay and nonmarriage have led to substantial reduction in fertility rates [36]. The trend in second births closely follows that of first births and there has not been a major decline in second births. Thus the contribution of second births to overall fertility decline has been minimal. There appears to be a strong two-child norm even in regions where fertility is low, and there are no indications that this is changing. As long as marriage continues to be universal and the two-child norm common, it is unlikely that fertility would decline to very low levels in India.

Although fertility has declined to below replacement in several states, it is still common for women to have at least two children. While the possibility of further fertility reductions cannot be ruled out, the current socioeconomic and cultural situation is not conducive for such a scenario. In parts of Asia (especially East Asia) where fertility has reached very low levels, fertility decline was preceded or accompanied by steep increase in women's labor force participation rates in the formal economy, restructuring of family relations, normative changes, and growing acceptance of singlehood. India has undergone rapid economic changes over the last two decades and this has provided women with new employment opportunities not available before. While women in increasing numbers are participating in the labor force, the changes have not been rapid and appear not to have dented the strong patriarchal bent in family relations nor has it eroded the primacy of family and kinship relationships. Unless there are widespread and dramatic changes in the traditional institutions and structure fertility might not decline to very low levels.

Regional differences matter for several reasons. If the current pattern continues, most of population growth will occur in high-fertility regions. This will lead to a larger share of the national population living in these areas. As James [37] has observed this might lead to social turbulence and political instability in the country. Additionally, such demographic imbalances might result in increased internal migration from the high-fertility regions to the low-fertility regions and this might create social tensions. Regions with high fertility also fare poorly when compared to other regions in economic and social development. Population growth can further hinder development unless the social and economic systems are improved to provide education and labor opportunities for the growing population. This paper did not cover in detail the causes and pathways of fertility reduction in the low-fertility regions. In terms of policy, much can be learned by looking at these pathways and applying them to the high-fertility regions.

\section{References}

[1] T. Spoorenberg, "Fertility transition in India between 1977 and 2004: analysis using parity progression ratios," PopulationE, vol. 65, no. 2, pp. 314-332, 2010.

[2] International Institute for Population Sciences (IIPS) and Macro International, National Family Health Survey (NFHS3), 2005-06: India, vol. 1, IIPS, Mumbai, India, 2007.

[3] N. M. P. Bhat, "India's changing dates with replacement fertility: a review of recentfertility trends and future prospects," in Proceedings of the UN Expert Group Meeting on Completing the Fertility Transition, New York, NY, USA, 2002.

[4] S. I. Rajan, "Introduction: emerging demographic change in South India," in Fertility Transition in South India, C. Z. Guilmoto and S. I. Rajan, Eds., pp. 23-53, Sage Publications, New Delhi, India, 2005.

[5] H. Narayanan, "Women's health, population control and collective action," Economic \& Political Weekly, vol. 46, no. 8, pp. 39-47, 2011. 
[6] C. Z. Guilmoto, "Demography for anthropologists: populations, castes, and classes," in A Companion to the Anthropology of India, I. Clark-Decès, Ed., pp. 25-44, Blackwell Publishing, UK, 2011.

[7] T. Dyson and M. Moore, "On kinship structure, female autonomy, and demographic behavior in India," Population \& Development Review, vol. 9, no. 1, pp. 35-60, 1983.

[8] P. Dommaraju and V. Agadjanian, "India's north-south divide and theories of fertility change," Journal of Population Research, vol. 26, no. 3, pp. 249-272, 2009.

[9] M. Saavala, "Below replacement-level fertility in conditions of slow social and economic development: a review of the evidence from South India," Finnish Yearbook of Population Research, vol. 45, pp. 45-66, 2010.

[10] K. Nagaraj, "Extent and nature of fertility decline in Tamil Nadu," Review of Development and Change, vol. 4, pp. 89-120, 1999.

[11] K. S. James, "Fertility decline in Andhra Pradesh: a search for alternative hypotheses," Economic and Political Weekly, vol. 34, no. 8, pp. 491-499, 1999.

[12] International Institute for Population Sciences (IIPS), District Level Household and Facility Survey (DLHS-3), 2007-08: India, IIPS, Mumbai, India, 2010.

[13] Z. Matthews, S. S. Padmadas, I. Hutter, J. McEachran, and J. J. Brown, "Does early childbearing and a sterilization-focused family planning programme in India fuel population growth?" Demographic Research, vol. 20, pp. 693-720, 2009.

[14] S. S. Padmadas, I. Hutter, and F. Willekens, "Compression of women's reproductive spans in Andhra Pradesh, India," International Family Planning Perspectives, vol. 30, no. 1, pp. 12-19, 2004.

[15] P. Dommaraju, "Marriage and fertility dynamics in India," Asia-Pacific Population Journal, vol. 26, no. 2, pp. 21-38, 2012.

[16] M. E. John, "Census 2011: governing populations and the girl child," Economic \& Political Weekly, vol. 46, no. 16, pp. 10-12, 2011.

[17] D. Basu and R. De Jong, "Son targeting fertility behavior: some consequences and determinants," Demography, vol. 47, no. 2, pp. 521-536, 2010.

[18] A. Maharatna, "Fertility, mortality and gender bias among tribal population: an Indian perspective," Social Science and Medicine, vol. 50, no. 10, pp. 1333-1351, 2000.

[19] A. M. Basu and S. Amin, "Conditioning factors for fertility decline in Bengal: history, language identity, and openness to innovations," Population and Development Review, vol. 26, no. 4, pp. 761-794, 2000.

[20] S. Dey and S. Goswami, "Fertility pattern and its correlates in North East India," Journal of Human Ecology, vol. 26, no. 2, pp. 145-152, 2009.

[21] S. J. Jejeebhoy and S. Kulkarni, "Reproductive motivation: a comparison of wives and husbands in Maharashtra, India," Studies in Family Planning, vol. 20, no. 5, pp. 264-272, 1989.

[22] C. Z. Guilmoto, "Fertility decline in India: maps, models and hypotheses," in Fertility transition in South India, C. Z. Guilmoto and S. I. Rajan, Eds., pp. 385-435, Sage, India, New Delhi, India, 2005.

[23] C. Z. Guilmoto and S. I. Rajan, Eds., Fertility transition in South India, Sage, New Delhi, India, 2005.

[24] International Institute for Population Sciences (IIPS), National Family Health Survey (MCH and Family Planning), India 1992-93, IIPS, Bombay, India, 1995.

[25] International Institute for Population Sciences (IIPS) and ORC Macro, National Family Health Survey (NFHS-2), India 1998-99, IIPS, Mumbai, India, 2000.
[26] G. Feeney, "Population dynamics based on birth intervals and parity progression,” Population Studies, vol. 37, no. 1, pp. 7589, 1983.

[27] G. Feeney and Jingyuan Yu, "Period parity progression measures of fertility in China," Population Studies, vol. 41, no. 1, pp. 77-102, 1987.

[28] M. N. Bhrolcháin, "Period parity progression ratios and birth intervals in England and Wales, 1941-1971: a synthetic life table analysis," Population Studies, vol. 41, no. 1, pp. 103-125, 1987.

[29] A. Hinde, Demographic Methods, Arnold, London, UK, 1998.

[30] T. W. Pullum, "Natality. Measures based on censuses and surveys," in The Materials and Methods of Demography, J. S. Siegel and D. A. Swanson, Eds., pp. 407-428, Elsevier Academic Press, Amsterdam, The Netherlands, 2nd edition, 2004.

[31] T. W. Pullum, "An assessment of age and date reporting in the demographic and health surveys, 1985-2003," Demographic and Health Surveys Project, ORC Macro, Calverton, Md, 2006.

[32] J. E. Potter, "Problems in using birth-history analysis to estimate trends in fertility," Population Studies, vol. 31, no. 2, pp. 335-364, 1977.

[33] Census of India, Provisional Population Totals: Paper 1 of 2011, Office of the Registrar General \& Census Commissioner, New Delhi, India, 2011.

[34] Office of the Registrar General \& Census Commissioner, Population Projections for India and States, 2001-2026, National Commission on Population, New Delhi, India, 2006.

[35] United Nations, World Population Prospects: The 2010 Revisions, United Nations Population Division, New York, NY, USA, 2011.

[36] G. W. Jones, "Delayed marriage and very low fertility in Pacific Asia," Population and Development Review, vol. 33, no. 3, pp. 453-478, 2007.

[37] K. S. James, "India's demographic change: Opportunities and challenges," Science, vol. 333, pp. 576-580, 2011. 


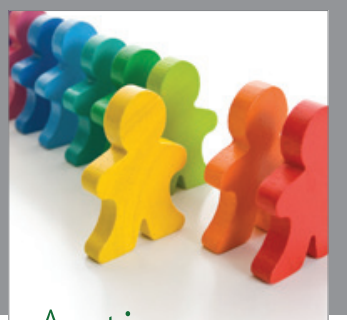

Autism

Research and Treatment
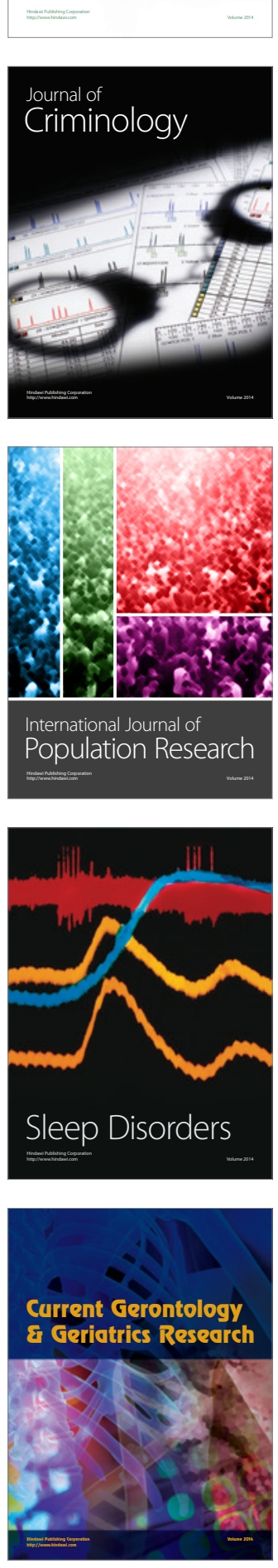
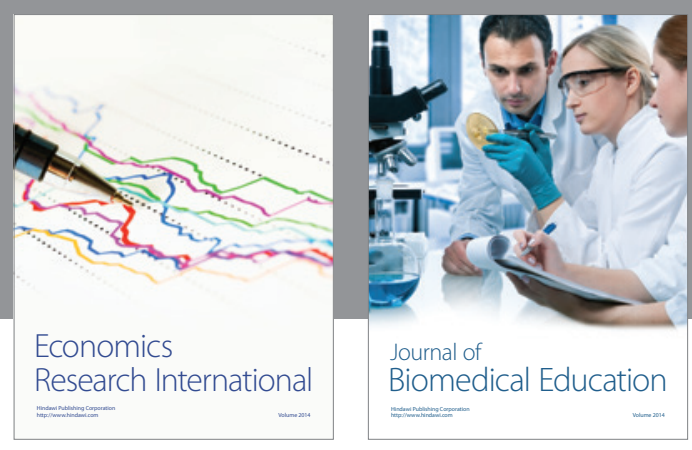

Journal of

Biomedical Education

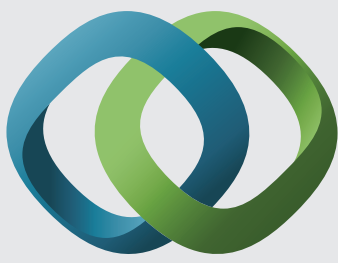

\section{Hindawi}

Submit your manuscripts at

http://www.hindawi.com
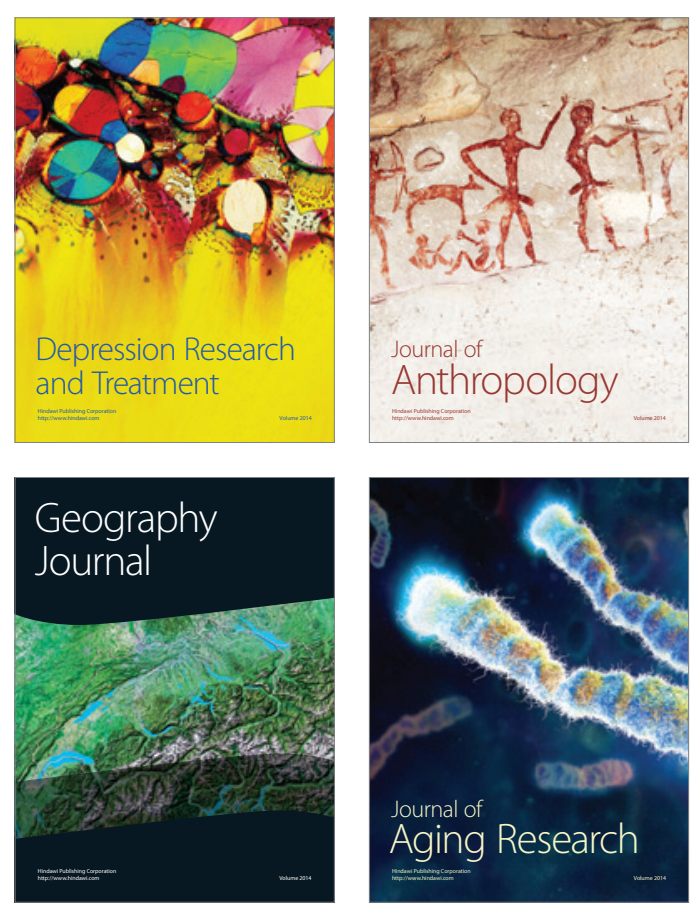

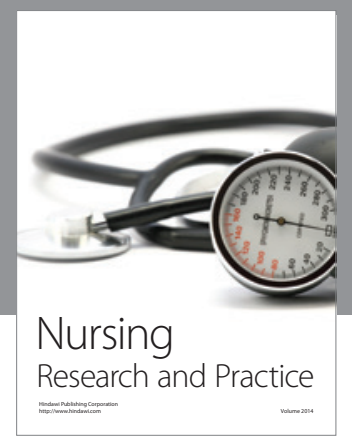

Nursing

Research and Practice

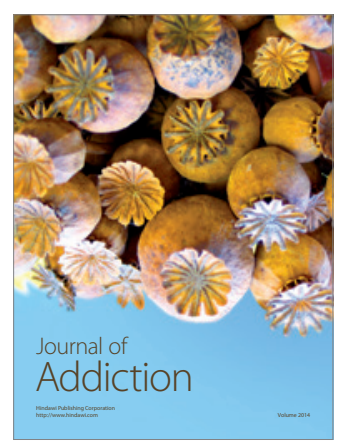

Child Development

Research

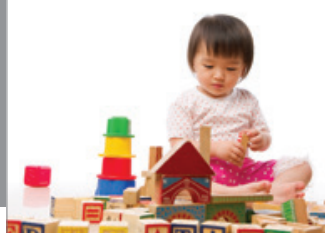

迥
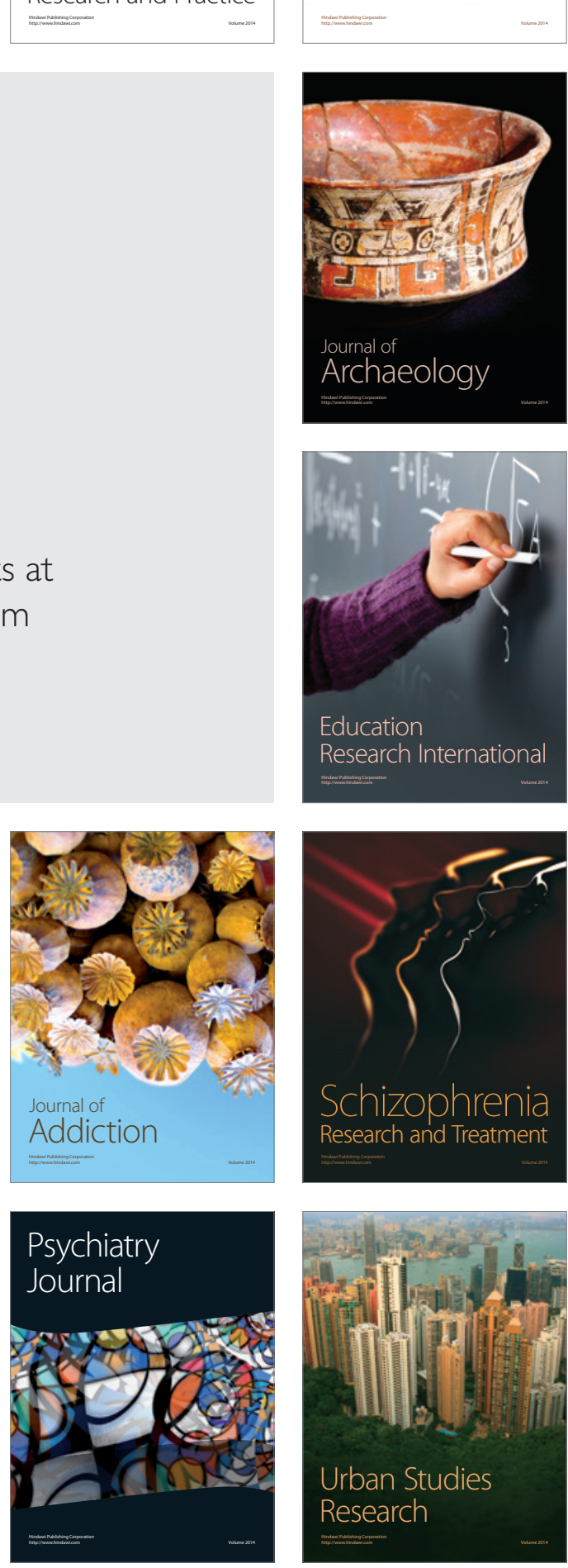